\title{
Oral and Written Transmission in Ethiopian Christian Chant
}

\section{Citation}

Shelemay, Kay Kaufman, Peter Jeffery, and Ingrid Monson. 1993. Oral and written transmission in Ethiopian Christian chant. Early Music History 12: 55-117.

\section{Published Version}

http://dx.doi.org/10.1017/S0261127900000140

\section{Permanent link}

http://nrs.harvard.edu/urn-3:HUL.InstRepos:3292407

\section{Terms of Use}

This article was downloaded from Harvard University's DASH repository, and is made available under the terms and conditions applicable to Other Posted Material, as set forth at http:// nrs.harvard.edu/urn-3:HUL.InstRepos:dash.current.terms-of-use\#LAA

\section{Share Your Story}

The Harvard community has made this article openly available.

Please share how this access benefits you. Submit a story.

\section{Accessibility}




\section{CAMBRIDGE \\ UNIVERSITY PRESS}

Oral and Written Transmission in Ethiopian Christian Chant

Author(s): Kay Kaufman Shelemay, Peter Jeffery, Ingrid Monson

Source: Early Music History, Vol. 12 (1993), pp. 55-117

Published by: Cambridge University Press

Stable URL: http://www.jstor.org/stable/853869

Accessed: 24/08/2009 21:27

Your use of the JSTOR archive indicates your acceptance of JSTOR's Terms and Conditions of Use, available at http://www.jstor.org/page/info/about/policies/terms.jsp. JSTOR's Terms and Conditions of Use provides, in part, that unless you have obtained prior permission, you may not download an entire issue of a journal or multiple copies of articles, and you may use content in the JSTOR archive only for your personal, non-commercial use.

Please contact the publisher regarding any further use of this work. Publisher contact information may be obtained at http://www.jstor.org/action/showPublisher?publisherCode=cup.

Each copy of any part of a JSTOR transmission must contain the same copyright notice that appears on the screen or printed page of such transmission.

JSTOR is a not-for-profit organization founded in 1995 to build trusted digital archives for scholarship. We work with the scholarly community to preserve their work and the materials they rely upon, and to build a common research platform that promotes the discovery and use of these resources. For more information about JSTOR, please contact support@jstor.org. 
Kay Kaufman Shelemay, Peter Jeffery

AND INGRID MONSON

\section{ORAL AND WRITTEN TRANSMISSION IN ETHIOPIAN GHRISTIAN CHANT*}

\section{In memory of Howard Mayer Brown}

Of all the musical traditions in the world among which fruitful comparisons with medieval European chant might be made, the chant tradition of the Ethiopian Orthodox Church promises to be especially informative. In Ethiopia one can actually witness many of the same processes of oral and written transmission as were or may have been active in medieval Europe. Music and literacy are taught in a single curriculum in ecclesiastical schools. Future

*This article is a revised and abridged synthesis of three separate papers presented at a session of the same title at the fifty-fourth Annual Meeting of the American Musicological Society at Baltimore, Maryland, in 1988. The material is drawn from a collaborative study carried out by the authors, for which Kay K. Shelemay served as project director, Peter Jeffery as project co-director and Ingrid Monson as research associate. The article has been edited by Kay K. Shelemay; sections written entirely by one member of the research team appear under his or her name, while the introductory and concluding remarks are drawn from all three articles. The authors acknowledge with gratitude a grant from the Research Division of the National Endowment for the Humanities, which supported their work, and the advice of Dr Getatchew Haile, who served as project consultant.

A note on transliteration of $\mathrm{G} \partial \partial^{c} \partial \mathrm{z}$ terms: The transliteration system used here eliminates most diacritical markings in order to reduce confusion with notational signs. The seven Ethiopic $\left(\mathrm{G} \partial^{\mathrm{e}} \partial \mathrm{z}\right)$ vowels (referred to as 'orders' when combined with one of the thirtythree basic symbols in the G $\partial^{c} \partial z$ syllabary) are represented as $\varepsilon, u, i, a, e, \partial$ and o. To avoid confusion in our transliteration of the written G $\partial^{\circ} \partial z$ sources, we have used $\varepsilon$ (pronounced 'like the sound one makes while hesitating in speaking and which is represented in writing by "uh", ' W. Leslau, Amharic Textbook (Wiesbaden, 1967), p. 6) for all first-order vowels. The reader should be aware that $\varepsilon$ is pronounced like that of the fourth-order (a) ('like the English exclamation "ah"' '; Leslau, p. 6) on the laryngeal consonants ('), ('), (K), (h'), (h). Additionally, the normally silent sixth-order vowel (pronounced "like the " $\mathrm{e}$ " in "roses" '; Leslau, p. 7) is often pronounced in musical performance, and the consonants it accompanies often carry notational symbols as well. For this reason, we have included in our transliterations many syllables with sixth-order vowels that would not be articulated in normal speech. Popular spellings are used for modern place, tribal and personal names. 
singers begin to acquire the repertory by memorising chants that serve both as models for whole melodies and as the sources of the melodic phrases linked to individual notational signs. At a later stage of training each one copies out a complete notated manuscript on parchment using medieval scribal techniques. But these manuscripts are used primarily for study purposes; during liturgical celebrations the chants are performed from memory without books, as seems originally to have been the case also with Gregorian and Byzantine chant. ${ }^{1}$ Finally, singers learn to improvise sung liturgical poetry according to a structured system of rules. If one desired to imitate the example of Parry and Lord, ${ }^{2}$ who investigated the modern South Slavic epic for possible clues to Homeric poetry, it would be difficult to find a modern culture more similar to the one that spawned Gregorian chant.

This article introduces the methods, materials and initial findings of a cross-disciplinary investigation of Ethiopian Christian chant. It was pointed out over twenty years ago that Ethiopian chant 'urgently needs investigating'. ${ }^{3}$ Although scholars have long studied the history, literature and liturgy of the Ethiopian church, ${ }^{4}$

As late as the fourteenth and fifteenth centuries in the West there were regulations obliging singers to perform without books (F. L. Harrison, Music in Medieval Britain, 4th edn (Buren, 1980), pp. 102-3). In the seventeenth century, Jacques Goar observed that 'while singing, the Greeks rarely look at, or even have, books written with musical notes' (E. Wellesz, A History of Byzantine Music and Hymnography, 2nd edn (Oxford, 1961, repr. 1971), pp. 4-5).

2 A. Lord, The Singer of Tales (Cambridge, MA, 1960, repr. New York, 1965).

3 F. L. Harrison, 'Music and Cult: the Functions of Music in Social and Religious Systems', Perspectives in Musicology, ed. B. S. Brook and others (New York, 1972), p. 315.

4 The principal study of Ethiopian church history is Taddesse Tamrat, Church and State in Ethiopia (Oxford, 1972). For the considerable resources on Ethiopian literature, see E. Cerulli, Storia della letteratura etiopica (Milan, 1956); enlarged 3rd edn, La letteratura etiopica (Florence, 1968); Getatchew Haile, 'Religious Controversies and the Growth of Ethiopic Literature in the Fourteenth and Fifteenth Centuries', Oriens Christianus, 4th series, 65 (1981), pp. 102-36, and 'A New Look at Some Dates in Early Ethiopian History', Le Muséon, 95/3-4 (1982), pp. 311-22. Ethiopian Christian liturgy is discussed in E. Hammerschmidt, Studies in the Ethiopic Anaphoras, 2nd rev. edn (Stuttgart, 1987); B. Velat, Soma Deggua, antiphonaire du carême, quatre premières semaines: texte éthiopien et variantes, Patrologia Orientalis 32/1-2 (Paris, 1966); idem, Études sur le Me eräf, commun de l'office divin éthiopien: introduction, traduction française, commentaire liturgique et musical, Patrologia Orientalis 33 (Paris, 1966); idem, Me erāf, commun de l'office divin éthiopien pour toute l'année: texte éthiopien avec variantes, Patrologia Orientalis 34/1-2 (Paris, 1966); idem, Șoma Deggua, antiphonaire du carême, quatre premières semaines: introduction, traduction française, transcriptions musicales, Patrologia Orientalis 32/3-4 (Turnhout, 1969); idem, 'Musique liturgique d'Éthiopie', Encyclopédie des musiques sacrées, ed. J. Porte, II (Paris, 1969), pp. 234-8. For a general history of the Ethiopian Church, see F. Heyer, Die Kirche Äthiopiens (Berlin, 1971). 
which was founded in the mid fourth century, Ethiopian Christian liturgical music has received only intermittent scholarly attention from Ethiopianists. ${ }^{5}$ The few investigations of Ethiopian sacred music (zema) in the musicological literature have combined data derived from Villoteau's landmark study with information from later secondary sources $^{6}$ and, occasionally, the writer's own observations. $^{7}$

To be sure, the $G \partial^{c} \partial z$ language presented a substantial barrier to musicologists wishing to explore the surviving manuscripts. But beyond issues of linguistic competence and area expertise looms a larger epistemological issue. While musicological scholarship developed a sophisticated methodology for deciphering musical notation in manuscripts, it relegated to the area of 'performance practice' considerations of the relationship of notation to the unwritten or 'oral' features of this music. Ethnomusicologists, on the other hand, gained considerable experience in understanding orally transmitted musical traditions but rarely studied the systems of musical notation in which some of these traditions were encoded. This paradoxical situation has begun to change, as medievalists have become interested in the processes of oral transmission and its relationship to the development of Western musical notation. ${ }^{8}$

5 A few Ethiopianists attempted to list the notational signs ( $m \partial l \partial k k \partial t)$ they found within manuscripts, but did not investigate the melodies with which the signs were associated: H. Zotenberg, Catalogues des MSS. éthiopiens de la Bibliothèque nationale (Paris, 1877); A. Dillmann, 'Verzeichnis der abessinischen Handschriften', Die Handschriftenverzeichnisse der Kgl. Bibliothek zu Berlin (Berlin, 1878), III, pp. 31-2 and Tafel III; M. Cohen, 'Sur la notation musicale éthiopienne', Studi orientalistici in onore di Giorgio Levi della Vida, I (Rome, 1956), pp. 199ff; Tito Lepisa, 'The Three Modes and the Signs of the Songs in the Ethiopian Liturgy', Proceedings of the Third International Conference of Ethiopian Studies, II (Addis Ababa, 1970), pp. 162-87. An exception is M. Villoteau, 'De la musique (1) des Abyssins ou Éthiopiens', Description de l'Égypte, xxxi (Paris, 1809), pp. 741-54, who both described the melodies of a small group of $m \partial l \partial k k \partial t$ performed by Ethiopian church musicians he interviewed in Egypt and transcribed several complete liturgical portions in Western notation. B. Velat (see note 4) published musical transcriptions of approximately half of the 500 melodies he recorded from informants during the preparation of his valuable studies of the Ethiopian liturgy (Études sur le Me eräf, and Soma Deggua, 1969) but he did not correlate each melody with its respective notational sign.

Notably F.-J. Fétis, Histoire (générale) de la musique, Iv (Paris, 1874), pp. 101-16.

E. Wellesz, 'Studien zur äthiopischen Kirchenmusik', Oriens Christianus, new series, 9 (1920), pp. 74ff; F. M. C. Mondon-Vidailhet, 'La musique éthiopienne', Encyclopédie de la musique et dictionnaire du Conservatoire, ed. A. Lavignac and L. de La Laurencie, I/5 (Paris, 1922), pp. 3179ff; M. Powne, Ethiopian Music: an Introduction (London, 1968); Ashenafi Kebede, 'La musique sacrée de l'Église Orthodoxe de l'Éthiopie', Éthiopie: musique de l'Église Copte (Berlin, 1969), pp. 3-14.

8 L. Treitler, 'Homer and Gregory: the Transmission of Epic Poetry and Plainchant', Musical Quarterly, 60 (1974), pp. 333-72, and “"Centonate” Chant: übles Flickwerk or E 
Meanwhile, ethnomusicologists have shown increasing interest in non-Western notational systems. ${ }^{9}$

There is no doubt that this longstanding methodological impasse contributed to the scholarly neglect of Ethiopian Christian chant, since the only plausible method for studying this music and its notation is to approach them through the surviving oral tradition. Otherwise, the musical meaning of the notational signs and the relationships between them cannot be ascertained. The study of Ethiopian Christian chant and its notational system presented here has as a result drawn upon methods and sources of both ethnomusicology and musicology. The combination of ethnographic, palaeographic and documentary evidence provides a much fuller picture than that possible through only a single disciplinary matrix or set of sources.

Our findings suggest that the Ethiopian oral and written sources have interacted in a flexible yet surprisingly stable manner from at least the sixteenth century to the present. In the following pages we set forth what we have learned of this interaction and trace the new perspectives it provides both of the history and modern practice of this particular chant tradition and of the nature of musical transmission in its relationship to liturgical development, individual creativity and cultural change. In the context of the recent debate on issues of oral transmission, oral composition, memory and the history of notation in Gregorian chant, ${ }^{10}$ the Ethiopian notational system also provides additional evidence that may be of broader interest to the scholarly community.

pluribus unus?', Journal of the American Musicological Society [hereafter JAMS], 28 (1975), pp. 1-23; H. Hucke, 'Toward a New Historical View of Gregorian Chant', JAMS, 33 (1980), pp. 437-67.

9 W. Malm, Japanese Music and Musical Instruments (Rutland, VT, and Tokyo, 1959); W. Kaufmann, Tibetan Buddhist Chant (Bloomington, IN, 1975); K. K. Shelemay, 'A New System of Musical Notation in Ethiopia', Ethiopian Studies for Wolf Leslau, ed. S. Segert and A. J. E. Bodrogligeti (Wiesbaden, 1983), pp. 571-82; T. Ellingson, 'Buddhist Musical Notations', The Oral and the Literate in Music, ed. Tokumaru Yosihiko and Yamaguti Osamu (Tokyo, 1986), pp. 302-41.

10 L. Treitler, 'The Early History of Music Writing in the West', JAMS, 35 (1982), pp. 237-79, and 'Reading and Singing: on the Genesis of Occidental Music-Writing', Early Music History, 4 (1984), pp. 135-208; D. Hughes, 'Evidence for the Traditional View of the Transmission of Gregorian Chant', JAMS, 40 (1987), pp. 377-404; K. Levy, 'Charlemagne's Archetype of Grergorian Chant', JAMS, 40 (1987), pp. 1-30, and 'On the Origin of Neumes', Early Music History, 7 (1987), pp. 59-90; A. E. Planchart, 'On the Nature of Transmission and Change in Trope Repertories', JAMS, 41 (1988), pp. 215-49; A. W. Robertson, 'Benedicamus Domino: the Unwritten Tradition', JAMS, 41 (1988), pp. 1-62. 
Oral and written transmission in Ethiopian Ghristian chant

\author{
KA Y KA UFMAN SHELEMA Y
}

USING MODERN SOURGES TO AGHIEVE

HISTORICAL REGONSTRUGTION IN THE

STUDY OF ETHIOPIAN CHRISTIAN GHANT

Theory, modern sources and methodology. Most studies of oral transmission, in both music and literature, ${ }^{11}$ have approached analysis through the examination of stereotyped musical or textual phrases, sometimes termed 'formulas', which are identified by the scholar through their repeated occurrence in surviving written sources. To the best of our knowledge, in prior studies the definition of these stereotyped phrases has been provided by the scholar studying a complete written 'text', whether of a Homeric epic or of a notated plainchant repertory.

In contrast, our analysis takes as its point of departure the smallest structural unit defined by the singer within the Ethiopian tradition we are studying. This unit is the $m \partial l \partial k k \partial t$ (sign) of the notational system. Each $m \partial l \partial k k \partial t$ consists of one or more members of the Ethiopic syllabary derived from the liturgical text of a wellknown 'portion', or section of the chant book known as the Daggwa, with which a particular melody is primarily associated; the $m \partial l \partial k k \partial t$ is placed immediately above words to which its associated melody should be sung. In the case of Ethiopian Christian chant, segmentation arrived at through these indigenous units also provides the critical link between oral and written aspects of the tradition: the $m \partial l \partial k k \partial t$ is at once an oral melody and a written sign. ${ }^{12}$

Our understanding of the Ethiopian musician's perception of the $m \partial l \partial k k \partial t$ was derived from oral and written materials I gathered during fieldwork in the Ethiopian capital, Addis Ababa, with $\varepsilon l \varepsilon q a$ Berhanu Makonnen, the musician in charge of all church musical activity and the accreditation of its musicians. $\mathrm{He}$ is a leading

11 In addition to Lord, The Singer of Tales, see also R. Finnegan, Oral Poetry (Cambridge, 1977), and Literacy and Orality (Oxford, 1988); W. Ong, Orality and Literacy (London, 1982); J. Goody, The Interface Between the Written and the Oral (Cambridge, 1977).

12 Although text and melody are effectively fused, this relationship arises from association within the context of a liturgical portion. No prosodic rules govern text-melody relations, nor does a particular segment of text serve in any way of which we are aware to generate its associated melody. 
Peter Jeffery, Ingrid Monson, Kay Shelemay

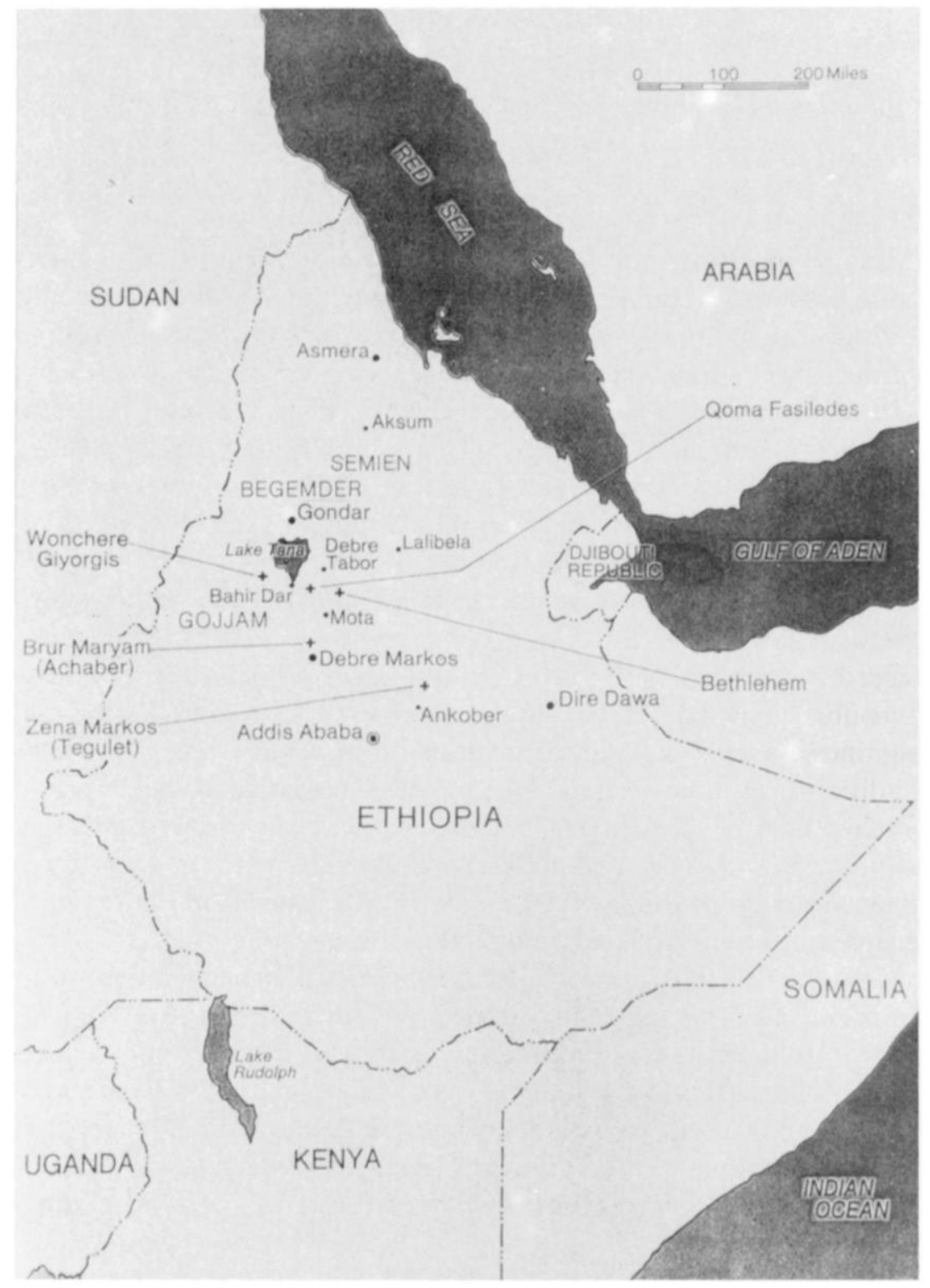

Figure l Map of Ethiopia 
exponent of the vocal style predominating in the modern church, called the 'Bethlehem style' after the northern Ethiopian monastery with which it is associated, and his knowledge and performance practice exemplify both normative and virtuoso aspects of the Ethiopian chant tradition. ${ }^{13}$

In addition to systematically explaining aspects of Ethiopian Christian liturgical and musical practice, and performing chants drawn from all the major service books for all occasions in the annual liturgical cycle, Eleqa Berhanu gave me a complete list of the notational signs ( $m \partial l \partial k k \partial t)$ that he had prepared for his classes at the Theological College in Addis Ababa and sang the melody associated with each sign. I tape-recorded all these sessions in full, which has facilitated the transcription, analysis and presentation of this material years after the primary research was completed.

Berhanu's list, of which I received a photocopy, was a mimeographed Amharic typescript on legal-size paper $(8.5 \times 14$ in $)$ incorporated within a longer document he had compiled entitled

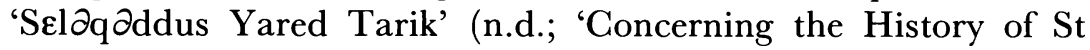
Yared', hereafter SYT). The remainder of SYT contains an account of the life of St Yared (see below for discussion of his significance), explanation of the modal system, portion types and additional notational signs. Berhanu reports that he compiled SYT for his second-year Theological College students and that the list of notational signs was derived from a combination of his received knowledge of the notational system and from a review of the signs found in notated manuscripts in his possession. ${ }^{14}$

Compiled in writing as well as performed, this composite oral and written document revealed to us the materials of the Ethiopian

13 Berhanu Makonnen is a third-generation debtera trained for thirty-one years in musical and liturgical studies, including twelve years at the Bethlehem monastery (see map, Figure 1). Following Ethiopian custom, we will often refer to him by his learned title, Eleqa, and his first name alone. To avoid bibliographic confusion, other Ethiopian scholars will be listed by their full names in first references.

14 Interview, 2 June 1975, and correspondence with the author, 15 December 1988. Berhanu Makonnen's SYT, including the list of notational signs, appears to rely at least in part on the source or sources also used to prepare an obscure Theological College

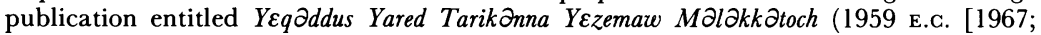
hereafter YYTYM]). The complicated relationship between these two documents is discussed in detail in K. K. Shelemay and P. Jeffery, Ethiopian Christian Liturgical Chant: an Anthology, I (Madison, WI, forthcoming). Germane to the discussion here is the fact that both SYT and YYTYM appear to be only two of several attempts to list systematically the notational signs beginning in the 1960 s, a development perhaps stimulated by pedagogical demands in the urban environment. 
Christian musical and notational system. Furthermore, the structure of Berhanu's testimony set forth irrefutable evidence that a

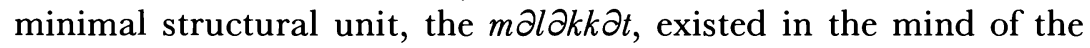
Ethiopian musician, providing both a central hypothesis and the basis of a working methodology for our research. However, our dependence upon Berhanu's list of $m \partial l \partial k k \partial t$ raised other issues regarding the goals of this study and the management of the data that merit discussion.

The first issue is the nature of the relationship between an individual's knowledge of a tradition and the dimensions of the musical system at large. We have chosen to rely upon Eleqa Berhanu's view of the Ethiopian musical system as the anchor of our project because it is the only feasible way to sketch the boundaries of a tradition that necessarily vary from person to person. On a broader cultural level as well, Ethiopian concepts of the importance of the individual and the consistent emphasis on and respect for hierarchy supports such an approach. ${ }^{15}$ This project therefore should be viewed on its most specific level as an effort to trace the major parameters of the normative Ethiopian Christian chant tradition in the late twentieth century, as understood and practised by one of its most accomplished musicians.

Aware of the limitations inherent in a study depending upon one main informant, I also recorded from Eleqa Berhanu and two other debteras (church musicians) the same sample of fifty-seven $m \partial l \partial k k \partial t$ and selected liturgical portions from different service books. The other two musicians lived in the Ethiopian capital but were trained

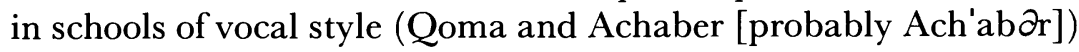
associated with two different monasteries in north-western Ethiopia. This comparative material, discussed below by Ingrid Monson, confirms the existence of a shared core of notational and performance practice that transcends individual knowledge and schools of training, while graphically demonstrating the range of variation acceptable in performance of the Ethiopian chant tradition.

A second issue raised by the data from the oral tradition relates to the complexity of the Ethiopian Christian musical system. The 558 notational signs are divided into three categories of mode $(s \partial l t$,

15 D. Levine, Wax and Gold (Chicago, 1965), pp. 75, 274. 
literally 'mode, manner, style'), ${ }^{16}$ or, more generally, zema, 'chant,

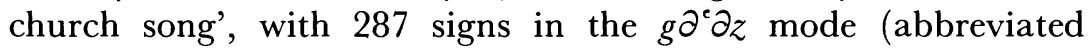
G1-287), 142 signs in Eraray (abbreviated Al-142), and 129 in ${ }^{\circ} \partial z l$ (abbreviated E1-129). The melodies associated with the signs are the building-blocks of the three modes and the smallest musical units discussed by Ethiopian Christian musicians. Thus issues of modality, which involve significant differences in pitch set, range, melodic contour, ornamentation and vocal style, become quite important in any discussion of the $m \partial l \partial k k \partial t$. Conversely, this study of the $m \partial l \partial k k \partial t$ necessarily serves to illuminate and define the parameters of mode in this musical tradition.

The notation also provides insight into many aspects of musical and liturgical structure. In addition to the $558 \mathrm{~m} \partial l \partial k k \partial t$, there is a group of 114 signs called bet (literally, 'house', abbreviated B1114), also derived from the syllabary. The bet appear in margins to indicate the 'family' of melody within a mode to which the particular chant melody belongs. There are also ten conventional signs, termed $y \varepsilon f i d \varepsilon l q \partial r s^{\prime}$, that prescribe aspects of articulation, attack, decay, or placement of individual pitches or melodic patterns; they appear as interlinear signs interspersed between the $m \partial l \partial k k \partial t$ (see Table 1). Yet another notational component is references within the texts to the halleluya tables ( $\varepsilon_{n q \varepsilon s^{\prime} \varepsilon \text { Halleta) that }}$ indicate to which melody a halleluya should be sung; these melodies derive from the bet system. A final type of notational symbol is a number placed in the margin, called madgam, which signals the singer to repeat that portion of text with instrumental accompaniment and dance. ${ }^{17}$ To understand the $m \partial l \partial k k \partial t$, therefore, is to confront the entire Ethiopian Christian musical system. Indeed, it can be argued that it is probably impossible to explicate fully Ethiopian Christian liturgical music without an understanding of the $m \partial l \partial k k \partial t$ and the other notational signs.

16 Definitions are drawn from W. Leslau, Concise Amharic Dictionary (Wiesbaden, 1976), pp. 48,179 . G $\partial^{e} \partial z$ ceased to be a spoken language about the twelfth or thirteenth century; much of the terminology for Ethiopian music theory is therefore actually in Amharic, a related language that has become the official vernacular of modern Ethiopia. 17 During the research sessions, all chants were sung without accompaniment as qum zema ('basic chant'). When performed in liturgical context during the offices that precede the Mass, certain chants are first sung unaccompanied and then repeated several times, accompanied in each subsequent rendition by the motion of the prayer staff (meqwamiya),

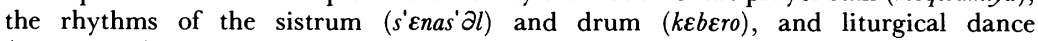
(Eqqwaqwam). 
Kay Kaufman Shelemay, Peter Jeffery, Ingrid Monson

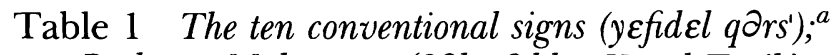
source: Berhanu Makonnen, 'Saleqaddus Yared Tarik', p. 7

\begin{tabular}{cccc}
\hline \hline yəzat & $\cdot$ & ch'əret & hədet \\
deret & $\ddots$ & qənat & ) \\
rəkrək & - & dərs (G261) & $\cap$ \\
dəfat & - & enbər & {[} \\
qərt' & & & \\
\hline \hline
\end{tabular}

a According to Berhanu Makonnen, ch'aret and qônat share a sign. Velat

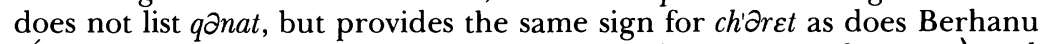

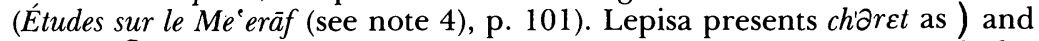
qanat as S (Lepisa, 'The Three Modes' (see note 5), p. 168). Although the cadential markers $d \partial r s$ and $\varepsilon n b \partial r$ are classified as conventional signs, they are represented by characters from the syllabary; $d \partial r s$ is additionally included in the list of $m \partial l \partial k k \partial t$ as G261.

A third issue relates to the sheer amount of material provided by Berhanu Makonnen. Eleqa Berhanu sang all the notational symbols in his repertory, including the bet and $y \varepsilon f i d \varepsilon l q \partial r s^{\prime}$, as well as over a thousand liturgical chants from the major service books. Because of the amount of material and the plethora of liturgical books and occasions involved, we decided to focus this initial inquiry primarily on the chants of the Doggwa, the most important collection as well as Berhanu Makonnen's primary area of specialisation. ${ }^{18}$ The Daggwa is performed before the Mass on Sundays and holidays throughout the liturgical cycle. These chants form the non-monastic or 'Cathedral' Office, the most important occasion for music in the Ethiopian liturgy.

Our intent was to gain an overview of musical practice while learning in as much detail as possible what we could of the development of the notational system. Since a 'reading' of notation in manuscripts is clearly impossible without knowledge of the oral

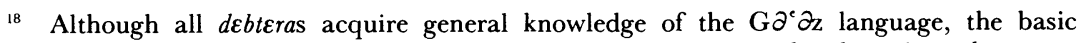
service books and zema, it is traditional for a singer to specialise later in at least one area. Eleqa Berhanu, although primarily a master of Daggwa and a leader of the musicians (marigeta), received additional diplomas in liturgical dance and several other service books, and was further ordained as a priest. 
Oral and written transmission in Ethiopian Christian chant

tradition, we numbered all signs of the notational system from Berhanu's list and transcribed their melodies in a 'dictionary'. We then used this apparatus to analyse eighteen sample portions, balancing the choice to incorporate (1) a cross-section of liturgical occasions; (2) a representative sampling of portion types; (3) examples from the three modal categories; and (4) inclusion of portions with possible concordances in other Ethiopian and Eastern Christian traditions. ${ }^{19}$

Since this study employs an unorthodox methodology of working from the contemporary oral tradition backwards into manuscript sources, it seems appropriate to detail here our analytical procedures. Using the dictionary of signs constructed from Eleqa Berhanu's list, I identified the signs in the modern printed $M \varepsilon s^{\prime} h^{\prime} a f \varepsilon D \partial g g w a^{20}$ from which Eleqa Berhanu sang. At the same time, I compared the dictionary entry for each sign with Eleqa Berhanu's realisation of the signs in performances of the complete portions, which I had also transcribed into Western musical notation. Meanwhile, Peter Jeffery used Berhanu Makonnen's list of signs to identify the $m \partial l \partial k k \partial t$ for each of the sample portions in a carefully selected group of manuscripts. After this first stage, we worked together to arrive at a final reading of the notation for each portion in all sources, checking Jeffery's reading of the notated manuscripts against my analysis of both the modern written sources and performance. We found that evidence from the dictionary of signs, the manuscripts, the modern notated books, musical transcriptions of complete portions, and Berhanu's explanations combined to provide an effective control on our readings of $m \partial l \partial k k \partial t$ from any single written source. Only occasionally were we unable to identify a sign after consulting our sources as well as the lists and transcriptions of signs prepared by others. ${ }^{21}$

Identification of the signs led in turn to consideration of a number of interpretative and historical issues. These can be illustrated briefly through discussion of one portion from our sample.

19 The many issues raised by the process of transcribing both the Ethiopian $m \partial l \partial k k \partial t$ and the eighteen sample portions into Western staff notation are too complex for treatment here and are discussed at length in Shelemay and Jeffery, Ethiopian Christian Liturgical Chant.

20 Addis Ababa (1950).

${ }^{21}$ Notably those of Lepisa ('The Three Modes') and Velat (Études sur le Meeräf, and Șoma Deggua, 1969). 
Example 1. First portion for St John's day, 1 Meskerem (source: performed by Berhanu Makonnen, 2 June 1975)
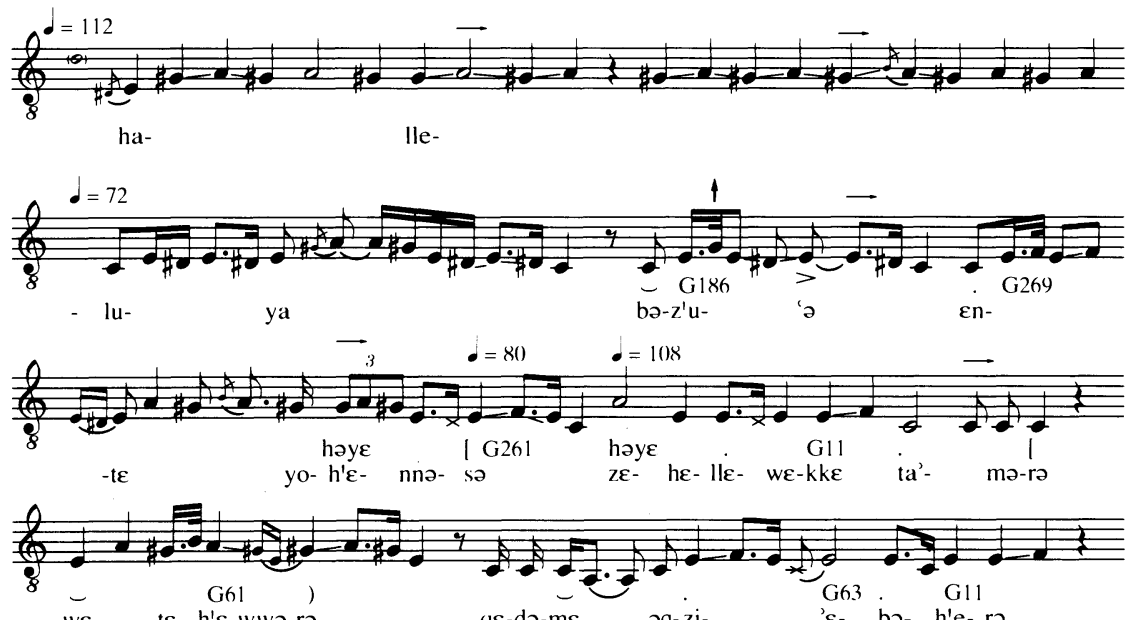
we -

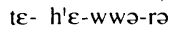
q $\varepsilon-\mathrm{d} ə-\mathrm{m} \varepsilon$
əg- zi-
' $\varepsilon$ - bə- h'e- ra
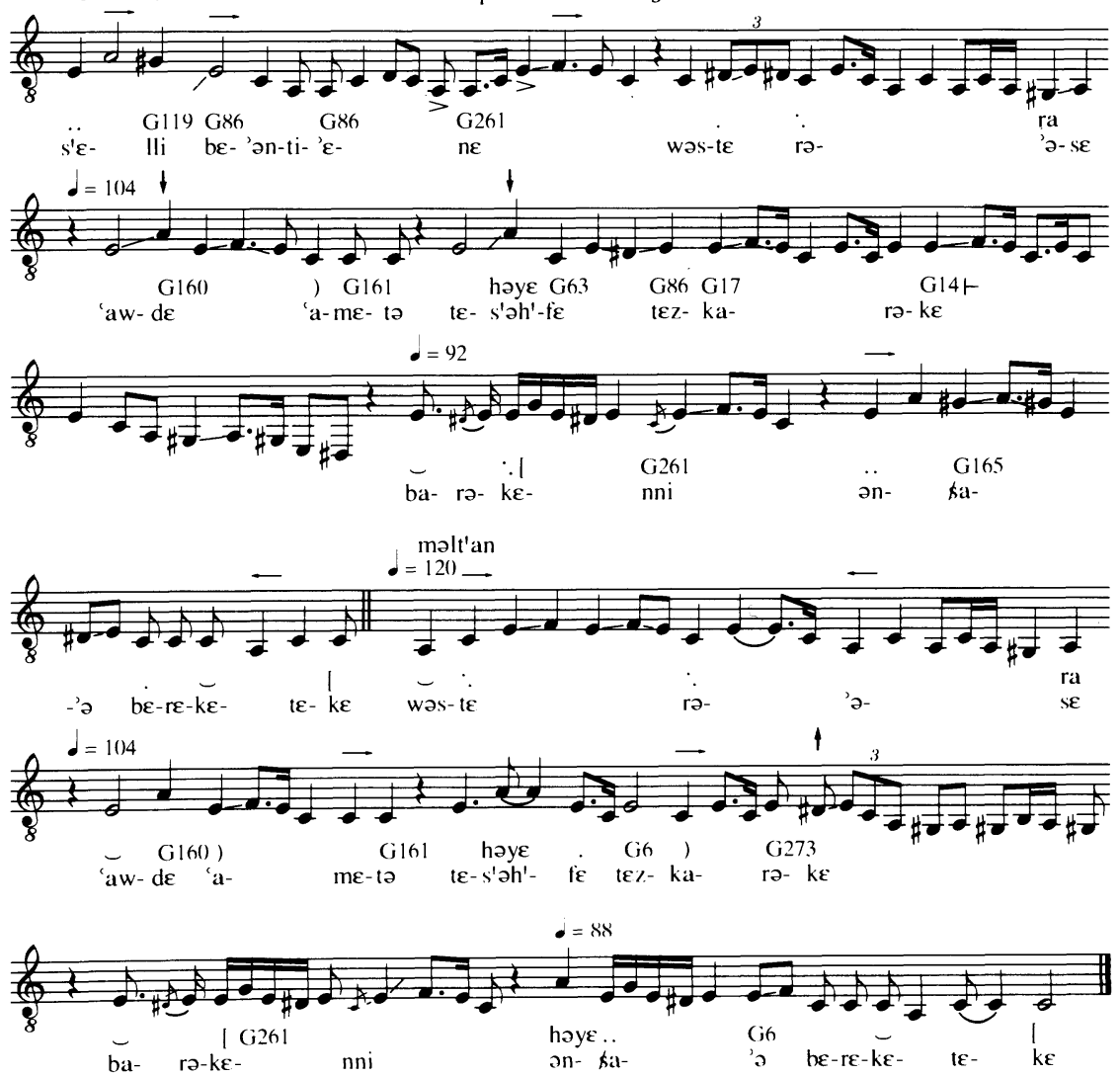
Oral and written transmission in Ethiopian Christian chant

Example 2. Bet 41 (source: performed by Berhanu Makonnen, 4 June 1975)

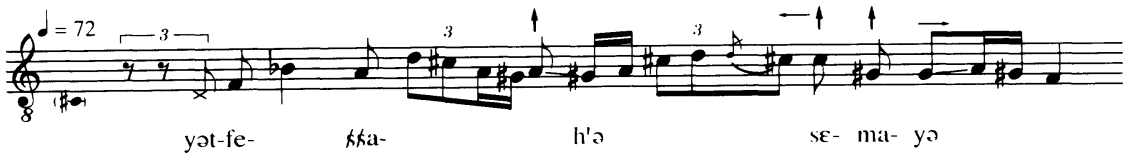

Issues in analysis and interpretation. Here we shall examine the first portion of the Daggwa, chanted on St John's day, the beginning of the liturgical year. ${ }^{22}$ This chant is of particular analytical interest because Berhanu Makonnen, at my request, sang both the entire portion and then its constituent signs in order. Berhanu's 'analysis' of the signs in this portion helped us to answer some questions, and raised others in turn.

This portion, here termed portion 1, is preceded by a halleluya that corresponds to the first entry in the Halleta table under 'one halleluya'. There is also a bet indicated for this portion in the lefthand margin, $y \partial$, B41 (see also Example 2). Comparison of Examples 1 and 2 indicate that the melody of the halleluya, ornamented with vocal slides termed $r \partial k r \partial k$, deviates considerably from the prescribed bet. This variation can probably be attributed to the tradition of elaborating chant incipits, especially one occurring at such an important point in the liturgy. This portion also contains separate notation at the end for a slightly varied repetition of the

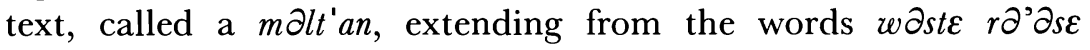
to the end. The malt'an notation here varies only on the words

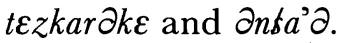

Although portion 1 contains a greater number of conventional

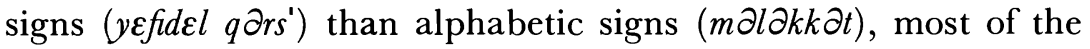
melodic activity can be accounted for by the $m \partial l \partial k k \partial t$ alone. Comparison of notation for this portion in the manuscripts and modern printed sources demonstrates that the same sign may be represented by different characters from the same source text. That is, in one manuscript the sign may consist of the first two characters of its source text, while in another it will be represented by the final two characters, or some other combination. Such an example from our demonstration portion 1 can be seen in the notation of

${ }^{22}$ See facsimile in Figure 2 and transcription in Western notation in Example 1. Peter Jeffery discusses the liturgical classification of this portion and its notational history below. 
Kay Kaufman Shelemay, Peter Jeffery, Ingrid Monson

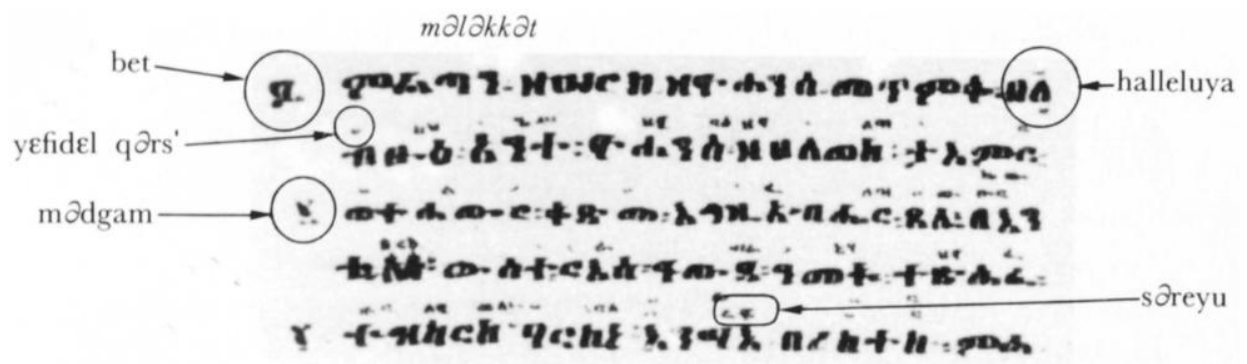

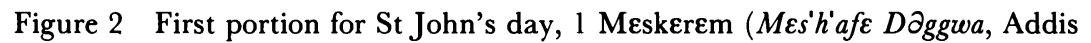
Ababa, 1959 E.c.)

Translation: In one: Blessed are you, John, who had to know and walk before God. Pray for us. Your memorial has been inscribed on the beginning of the year's cycle. Bless me so that I may receive your blessing. Malt' an: Your memorial has been inscribed on the beginning of the year's cycle. Bless me so that I may receive your blessing. (translation by Getatchew Haile)

G119 on the word $s^{\prime}$ clli. G119 is derived from the source text $\varepsilon w g \partial r$ ( h⿻ $\boldsymbol{g} \mathbf{C}$ ), and is most commonly represented by the sign $w \varepsilon$ $(\boldsymbol{\infty})$ as seen here in Figure 2. Yet in two of the manuscripts (16D and 18D, see Jeffery below) in our sample, G119 is represented by the sign $g \partial r(\boldsymbol{G} \boldsymbol{C})$. In this case, it appears that the notational symbol itself changed over time, yet regional custom or individual idiosyncrasy may provide equally plausible explanations for such differences in other instances.

Some $m \partial l \partial k k \partial t$ may be confused in manuscripts as well as in performance simply because their source words are similar. See G269 (geset, Example 3), the number which we have identified as

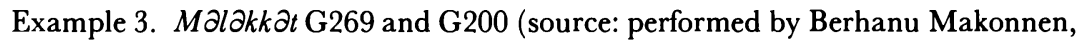
3 June 1975)

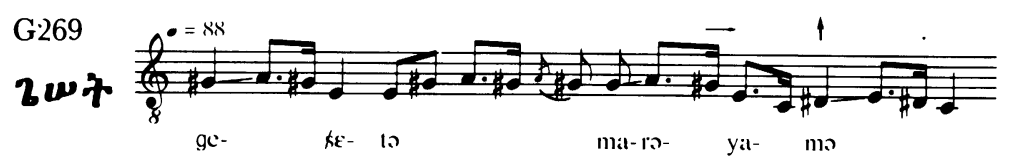

G200

$2 w$

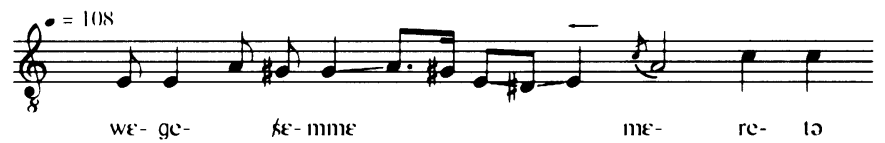


Oral and written transmission in Ethiopian Christian chant

the sign actually performed in the rendition transcribed in Example 1 despite the appearance of G200 (gese) in most of the manuscripts as well as the modern Doggwa (20D, shown in Figure 2) from which Eleqa Berhanu sang. Although Eleqa Berhanu read notation for $m \partial l \partial k k \partial t$ G200, he actually sang G269. While in this case we can confirm the substitution because Berhanu sang both the portion and its constituent signs separately, we believe this is not an uncommon event.

In some cases Eleqa Berhanu's performance suggests that an older melodic tradition persists despite a change in the notation. This may be true of the first sign in the portion, G186 (kah), which remains constant throughout its notational history except for the inclusion of sign G88 $\left(z^{\prime} u\right)$ in our MS 16A. Comparison of dictionary entries (see Example 4) with the modern performance (Example 1) indicates that the melody of G88 may actually match the modern performance as closely as that of G186.

Finally, in a number of cases, we have found a close melodic relationship between the dictionary entries for different signs used on the same word in a portion. For example, G11 $(l \varepsilon z)$ is consist-

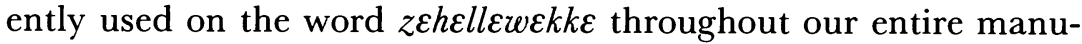
script sample, while in one modern service book the melodically similar G60 ( $q u)$ is substituted (see Example 5). Additionally, the

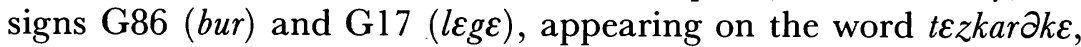
have similar melodies (see Example 6). Their use may represent an intentional redundancy or slightly different options presented to the singer. Similar close relationships may have existed between signs in the past as well, and thus signs with similar melodies may have been freely substituted for each other.

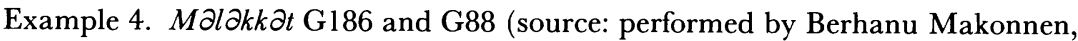
3 June 1975)

G186

hu

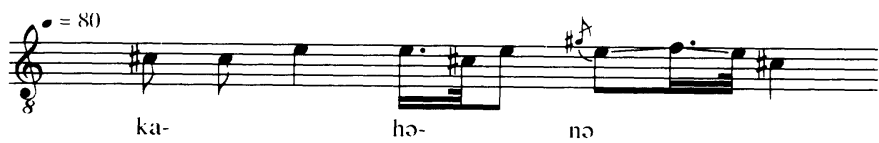

G88

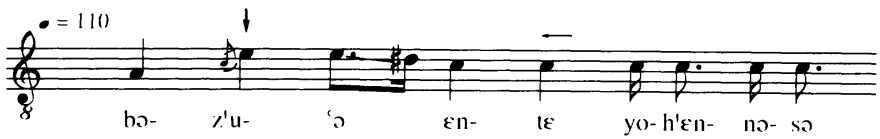




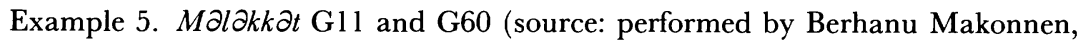
3 June 1975)

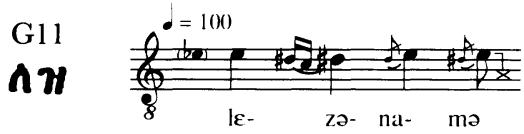

G60

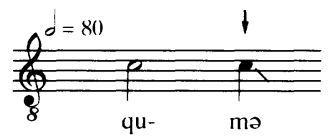

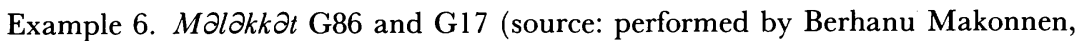
3 June 1975)

A. C.

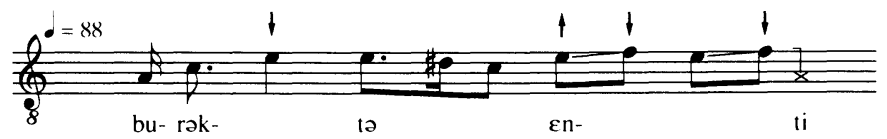

G17

n1

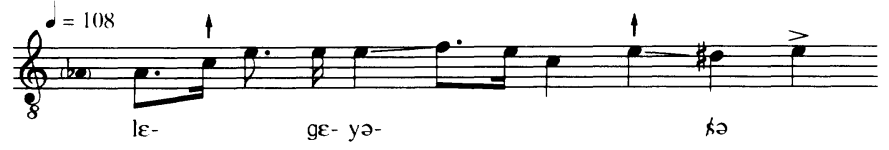

This brief analysis is intended to demonstrate that deciphering

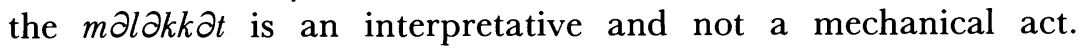
Berhanu's list of $m \partial l \partial k k \partial t$, and his performance of their melodies, provides a lens through which we can glimpse the inner workings of the Ethiopian Christian musical system. It allows us to describe the relationship between sign, source text and melody, and to reconstruct aspects of their interaction over time. Yet it must be emphasised that there is both intentional flexibility and unintentional confusion in use of the signs in manuscripts. Variation in performance practice by the singer introduces yet another level of differentiation that itself may eventually 'feed back' into the creation of a modified or new sign.

It is quite clear that the creativity of the individual musician is the critical link in the history of Ethiopian chant, with individuals 
Oral and written transmission in Ethiopian Christian chant

like Berhanu Makonnen serving to consolidate, perform and transmit their knowledge of the musical system and its notation to the next generation. An individual debtera, especially one whose own knowledge serves as a model for others, can indeed effect changes in chant performance and notation. A debtera selects the precise Daggwa portions to be performed on a given day from those of the required type and mode, and through this act may make decisions that ultimately promulgate specific texts and their associated melodies. As he copies his own D $\partial g g w a$, each man records his own understanding of the tradition in a source that may later influence others. Yet while the individual plays a potentially powerful role in transmitting and performing Ethiopian chant, and the system itself accommodates some flexibility, strong constraints have always encouraged and continue to guide the individual singer, who is taught to respect the models received from his own teacher, to obey the laws of the larger tradition of which he was a part and, ultimately, to revere the memory of St Yared.

\section{Oral and written sources for the history of Ethiopian chant.} Nowhere does the Ethiopian Christian musical tradition acknowledge the role of the individual more than in its collective commemoration of St Yared, to whose inspiration is attributed the genesis of the Ethiopian chant tradition in the sixth century. ${ }^{23}$ The Ethiopian Church celebrates a day each year in honour of St Yared, and colourful tales concerning his life and creative activity are recorded in the Ethiopian Synaxarion ${ }^{24}$ and the Gedle Yared $^{25}$.

Although oral traditions credit Yared with creating at least some of the $m \partial l \partial k k \partial t,{ }^{26}$ and a few written sources do mention music writing as one of his contributions, ${ }^{27}$ we have found no $m \partial l \partial k k \partial t$ in any manuscript dating before the sixteenth century. Therefore, traditions concerning two sixteenth-century church musicians who are

23 Getatchew Haile has recently questioned the traditional sixth-century chronology for Emperor Gebre Mesqel, to whose reign Yared's musical activity is attributed, and has proposed instead a late ninth-century dating ('A New Look', pp. 318-19).

${ }^{24}$ E. A. W. Budge, The Book of the Saints of the Ethiopian Church (Cambridge, 1928).

25 C. Conti Rossini, Acta Yāred et Pantalewon: scriptores aethiopici, Ix-X, Corpus Scriptorum Christianorum Orientalium 26-7 (Louvain, 1955).

26 Interview with Berhanu Makonnen (Addis Ababa, 1 September 1975).

27 A. Dillmann, Lexicon linguae aethiopicae (1865, repr. Osnabrück, 1970), p. 1130; Ministry of Information, Patterns of Progress: Music, Dance, Drama in Ethiopia (Addis Ababa, 1968), p. 25. 
said to have codified the notational system assume great significance.

An Ethiopian royal chronicle records that 'at the time of King Geladewos [1540-59] there appeared Azzaj Gera and Azzaj Ragu'el, priests trained in zema. And they began to make rules for

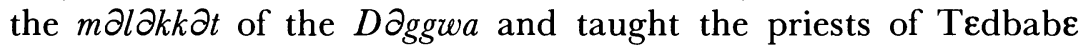
Maryam, which this prince had built' ${ }^{28}$ A manuscript (EMML 2045) copied at the northern Ethiopian monastery of Hayq during the reign of Emperor Iyasu 1 (1682-1706) presents a somewhat different and lengthier description concerning Gera and Ragu'el's contribution, attributing it to a command of Emperor Sers' $\varepsilon$ Dangəl (1563-97) and crediting the clerics with revising the Daggwa in the face of opposition within the church at that time. ${ }^{29}$

Documentary sources therefore strongly suggest that the clerics who lived and worked immediately following the Muslim invasion of Ethiopia (1529-41) were responsible at the very least for reconstruction and revision of the Ethiopian Christian notational system. This invasion, which led to the widespread destruction of churches and monasteries, and deprived Ethiopia of much of its literary heritage, must have severely disrupted liturgical performance and musical transmission.

In addition to the documentary sources, oral traditions also point to the mid sixteenth century as a period of revival in the church musical tradition. The pre-eminence of the musical style associated with the Bethlehem monastery is said to date from that period, precisely because it was the only place a notated $D \partial g g w a$ survived the Muslim invasion. ${ }^{30}$ Both the documentary sources and

28 R. Basset, 'Études sur l'histoire d'Éthiopie', Journal Asiatique, 7th series, 17 (1881), p. 336 .

29 EMML 2045 is described in G. Haile and W. Macomber, A Catalogue of Ethiopian Manuscripts Microfilmed for the Ethiopian Manuscript Microfilm Library, Addis Ababa, and for the Hill Monastic Music Library (Collegeville), vi (Collegeville, MN, 1982), p. 42. Other manuscripts provide similarly conflicting information. A chronicle cited in Velat, Soma Deggua (1966), p. 98, dates the two clerics to the reign of Geladewos (1540-59), while the rule of Sers' $\varepsilon$ Dangal is given in a St Petersburg MS described in C. Conti Rossini, 'Aethiopica (IIa Series)', Rivista degli Studi Orientali, 10 (1925), pp. 515-16, after B. Turaev, Ethiopskiya rukopisi v S.-Peterburge [Ethiopian Manuscripts in St Petersburg; in Russian], Zapiski Vostochnago Otdeleniya Imperatorskago Russkago Arkheologicheskago Obshchestva [Memoirs of the Oriental Section of the Imperial Russian Archaeological Society] 17 (1906), pp. 179-82.

30 Berhanu Makonnen transmits a genealogy of Yared's successors and credits a debtera named Lassane Bphrat, a student dated by oral tradition to the eighth generation after Yared, with having notated a Daggwa during the reign of Emperor Zer'a Ya ${ }^{\circ} \partial$ qob 
Oral and written transmission in Ethiopian Christian chant

surviving oral traditions therefore do at least raise the possibility that the sixteenth-century notational innovations may have drawn upon a pre-invasion model, perhaps one that arose a century earlier as part of an enormous surge of literary activity during the reign of Emperor Zer'a Ya 2 qob (1434-68). However, we have not yet found any other firm evidence for this earlier dating.

We therefore suggest that many aspects of the modern notational system, as well as the hegemony of the Bethlehem musical style, date primarily from a period of renewal beginning after the Muslim invasion in the mid to late sixteenth century. Notation evidently emerged within a relatively short period after a major calamity, setting into motion a period of innovation that climaxed in the seventeenth century. Below, Peter Jeffery sets forth the manuscript evidence supporting this hypothesis.

Harvard University

\section{PETER JEFFERY}

\section{THE MANUSGRIPT EVIDENGE$$
\text { ( I 3TH-2OTH GENTURIES) }
$$

Because the following discussion is the first attempt to trace the history of Ethiopian chant from written primary sources, it can do no more than locate tentatively some of the most prominent chronological landmarks in what has up to now been almost completely uncharted territory. In order to provide some objective basis for dating the various features of the chant and tracing their development, it was necessary first to assemble a corpus of datable chant manuscripts going back as far as possible. This was done by consulting published manuscript catalogues; the manuscripts chosen are listed in Table 2. While a few of the manuscripts listed

(1434-68). According to this tradition, only Lassane Jphrat's notated Daggwa survived the Islamic invasion in a place near the Bethlehem monastery. As a result, the emperor decreed that Bethlehem should be the place where Daggwa training would be centred (interview, 3 September 1975, and SYT, p. 4). Others have gathered similar traditions, including one concerning a search for surviving liturgical books during the reign of Emperor Sers' $\varepsilon$ Dangal (1563-97) which discovered a Daggwa and other service books at the Bethlehem monastery (B. Velat, 'Chantres, poètes, professeurs: les dabtara éthiopiens', Cahiers Coptes, no. 5 (Cairo, 1954), p. 27). 
Kay Kaufman Shelemay, Peter Jeffery, Ingrid Monson

Table 2 Ethiopian chant manuscripts arranged chronologically

\begin{tabular}{|c|c|c|c|}
\hline Siglum & Date (A.D.) & MS no. & Contents \\
\hline $13 A^{a}$ & XII-XIII ${ }^{b}$ & EMML 7078 & $\begin{array}{l}\varepsilon \text { rba }{ }^{i} \text { arranged } \\
\text { by melodic group }\end{array}$ \\
\hline $14 A^{a}$ & XIV & EMML 6944 & Mz, liturgical order \\
\hline $\begin{array}{l}15 \mathrm{~A}^{\mathrm{a}} \\
15 \mathrm{~B}^{\mathrm{a}} \\
15 \mathrm{C}^{\mathrm{a}}\end{array}$ & $\begin{array}{l}\text { XIV-XV } \\
\text { XV } \\
\text { XV }\end{array}$ & $\begin{array}{l}\text { EMML } 2095 \\
\text { Paris, BN, eth. } 92 \\
\text { Vatican Aeth. } 28\end{array}$ & $\begin{array}{l}\varepsilon \text { rba } t \text {, liturgical order } \\
\text { several collections } \\
D, S D \text { (incomplete) }\end{array}$ \\
\hline $\begin{array}{l}16 \mathrm{~A} \\
16 \mathrm{~B} \\
16 \mathrm{C}^{\mathrm{a}} \\
16 \mathrm{D}\end{array}$ & $\begin{array}{l}\text { XV-early XVI } \\
\text { XVI } \\
\text { XVI } \\
\text { late XVI }\end{array}$ & $\begin{array}{l}\text { EMML } 4667 \\
\text { EMML } 1894 \\
\text { EMML } 2468, \text { ff. } 143-6 \\
\text { EMML } 2542\end{array}$ & $\begin{array}{l}\mathrm{D}, \mathrm{SD} \\
\mathrm{D}, \mathrm{SD}, \mathrm{Mr}(\mathrm{T} \varepsilon \text { gulet?) } \\
\mathrm{D} \text { fragments } \\
\mathrm{D}, \mathrm{SD}, \mathrm{Mr}, \mathrm{Mw}\end{array}$ \\
\hline $\begin{array}{l}17 \mathrm{~A} \\
17 \mathrm{~B} \\
17 \mathrm{C}\end{array}$ & $\begin{array}{l}1653-4 \\
1682-93 \\
1695-6\end{array}$ & $\begin{array}{l}\text { EMML } 3400 \\
\text { EMML } 2077 \\
\text { EMML } 2045\end{array}$ & $\begin{array}{l}\mathrm{D} \\
\mathrm{Mr}, \mathrm{Mw}, \mathrm{Zm} \\
\mathrm{D}, \mathrm{SD} \text { (revision } \\
\quad \text { dated 1563-97) }\end{array}$ \\
\hline $\begin{array}{l}18 \mathrm{~A} \\
18 \mathrm{~B} \\
18 \mathrm{C} \\
18 \mathrm{D} \\
18 \mathrm{E}\end{array}$ & $\begin{array}{l}1755-61 \\
1755-69 \\
1760 \\
1787-8 \\
1779-1800\end{array}$ & $\begin{array}{l}\text { EMML } 2474 \\
\text { EMML } 3440 \\
\text { EMML } 512 \\
\text { EMML } 759 \\
\text { EMML } 2519\end{array}$ & $\begin{array}{l}\text { SD, ab Mr for Lent } \\
\mathrm{D}, \mathrm{Mr}, \mathrm{Mw}, \mathrm{Zm} \\
\mathrm{D}, \mathrm{SD}, \varepsilon \text { ryam list } \\
\mathrm{D} \\
\mathrm{SD}, \dot{\mathrm{Mr}} \text { for Lent }\end{array}$ \\
\hline $\begin{array}{l}19 \mathrm{~A} \\
19 \mathrm{~B} \\
19 \mathrm{C} \\
19 \mathrm{D}\end{array}$ & $\begin{array}{l}1800 \\
1820-1 \\
1884 \\
\text { XIX }\end{array}$ & $\begin{array}{l}\text { EMML } 3160 \\
\text { EMML } 2368 \\
\text { EMML } 35 \\
\text { EMML } 2936\end{array}$ & $\begin{array}{l}\mathrm{D} \\
\mathrm{D}, \mathrm{SD} \\
\mathrm{D}, \mathrm{SD} \\
\text { treatise on } \mathrm{D}, \\
\quad \text { Bethlehem school }\end{array}$ \\
\hline $\begin{array}{l}20 \mathrm{~A} \\
20 \mathrm{~B} \\
20 \mathrm{C} \\
20 \mathrm{D} \\
20 \mathrm{E} \\
20 \mathrm{~F} \\
20 \mathrm{G} \\
20 \mathrm{H}\end{array}$ & $\begin{array}{l}1917,1919-21 \\
1936-41 \\
X X \\
1947-50 \\
X X \\
1957-8 \\
X X \\
1975\end{array}$ & 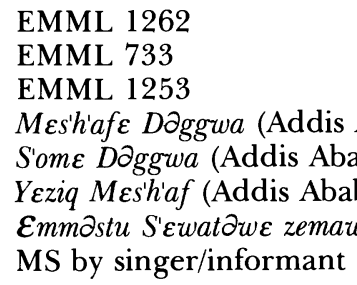 & $\begin{array}{l}\text { D, Bethlehem school } \\
\text { D, SD, Bethlehem } \\
\text { Mz, YT } \\
\text { Ababa, 1966-7) } \\
\text { aba, 1968) } \\
\text { ba, 1970) } \\
\text { voch (Addis Ababa, 1968) } \\
\text { of Achaber school }\end{array}$ \\
\hline
\end{tabular}

Key to abbreviations: $\mathrm{ab}=$ Abbreviated $\quad \mathrm{D}=\mathrm{D} \partial \mathrm{ggwa}$

$\mathrm{EMML}=$ Ethiopian Manuscript Microfilm Library, Collegeville, Minnesota $\mathrm{Mw}=\mathrm{M} \varepsilon$ was $\partial^{\circ} \mathrm{t} \quad \mathrm{Mz}=\mathrm{M} \varepsilon \mathrm{zmur} \quad \mathrm{Mr}=\mathrm{M} \partial^{\circ} \mathrm{raf}$

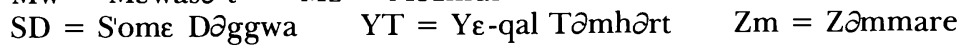

a These sources have little or no musical notation.

b Roman numerals denote centuries. 
Oral and written transmission in Ethiopian Christian chant

are owned by European libraries, the majority are widely scattered in many locations throughout Ethiopia, some of them quite inaccessible rural monasteries. Fortunately these are available on microfilm through EMML, the Ethiopian Manuscript Microfilm Library in Addis Ababa and Collegeville, Minnesota. ${ }^{31}$ From the seventeenth century to the present it was possible to select sources that can be dated to a very short span of years, because they contain prefaces or colophons that give specific dates or name the reigning kings and bishops. No such information is found in the extant manuscripts of the thirteenth to fifteenth centuries, which can only be dated more broadly by means of palaeographical evidence. However for this early period almost every known manuscript of the main chant collection (the Doggwa) has been included in the list. ${ }^{32}$ Ethiopian manuscripts older than the fifteenth century are quite rare; most of the earlier sources that may once have existed seem to have been destroyed in the wars with Muslim and other invaders that took place at that time.

The formation of the Ethiopian chantbook (DJggwa). The Ethiopian repertory contains about two dozen categories of chants that Western scholars like to call 'antiphons', because they somewhat resemble the antiphons of Gregorian chant in length and textual content. The Ethiopian word for them ( $r^{3} \partial s t \varepsilon$ D $\partial g$ grwa) means 'chapters' or 'portions', that is to say sections of the complete chant

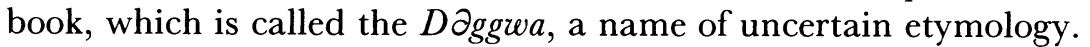
It is impossible to say precisely how many categories ${ }^{33}$ because

${ }^{31}$ For information on this very important microfilming project, see Haile and Macomber, A Catalogue of Ethiopian Manuscripts (Collegeville, MN, 1975-); also W. Macomber, 'The Present State of the Microfilm Collection of the Ethiopian Manuscript Microfilm Library', Ethiopian Studies: Proceedings of the Sixth International Conference, Tel Aviv, 14-17 April 1980, ed. G. Goldenberg (Rotterdam and Boston, 1986).

32 One MS that was not included is a Daggwa of the sixteenth or seventeenth century, listed as MS 24 in J. Flemming, 'Die neue Sammlung abessinischer Handschriften auf der Königlichen Bibliothek zu Berlin', Zentralblatt für Bibliothekswesen, 23 (1906), p. 13. Another, Uppsala, Universitetsbiblioteket MS O Ethiop. 37 is a $S^{\prime \prime}$ ome Daggwa copied some time between the mid sixteenth and the late seventeenth century. See O. Löfgren, Katalog über die äthiopischen Handschriften in der Universitätsbibliothek Uppsala (Stockholm, 1974), pp. 75-9; S. Uhlig, Äthiopische Paläographie, Äthiopistische Forschungen 22 (Stuttgart, 1988), pp. 445, 539-40.

33 The number of genres is said to be 22 in the Amharic treatise in Vatican City, Biblioteca Apostolica Vaticana, Cod. Aeth. 244, fols. 9-12; see S. Grébaut and E. Tisserant, Codices aethiopici vaticani et Borgiani, Barberinianus Orientalis 2, Rossianus 865, 2 vols. (Vatican City, 1935-6), p. 754. Velat (Soma Deggua, 1969, pp. xv-xviII) also gives this number, but shows that some genres have more than one name, or fall into subgroups with different names. 
Kay Kaufman Shelemay, Peter Jeffery, Ingrid Monson

Table 3 The main types of portion or 'antiphon' in Ethiopian chant

I. Used to begin an office hour or a structural unit within an office hour:

A. Wazema ('Vespers'), sung at the beginning of Vespers

B. Mezmur ('Psalm'), sung at the beginning of Sunday Matins

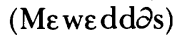

C. Ebun ('Our Father'), sung at the beginning of Lauds and the Little Hours on weekdays

D. 'azl (named for its mode), sung at the beginning of Lauds (Sabh' $\varepsilon$ t $\varepsilon$ negh)

II. Ecstatic chants which precede some of the above types on certain days:

A. Eryam ('Highest Heaven') can precede mezmur or abun

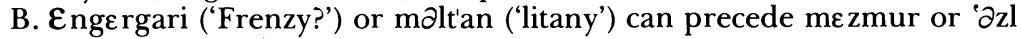
or even replace wazema

C. Masbak ('Proclamation') can precede wazema

III. Chants preceded by the refrain of Ps 135 [136]: 'Quoniam in aeternum misericordia eius [For his mercy endures forever]':

A. $\exists$ sme l $\varepsilon$-'al $\varepsilon \mathrm{m}$ ('Quoniam in aeternum'), sung at Lauds

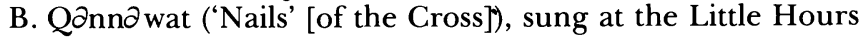

IV. Chants named for the type of stanza used in the accompanying psalm:

A. B $\varepsilon-h \varepsilon m m \partial$ stu ('in 5 '), with stanzas of five lines

B. $\varepsilon$ rba't ('fourth'), with stanzas of four lines

C. Sclest ('third'), with stanzas of three lines

V. Chants sung with specific psalms or canticles of the Ethiopian Psalter, from the incipits of which they take their names:

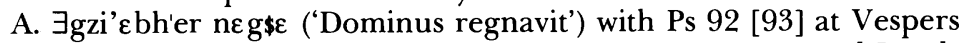

B. Yatbarck ('Benedictus') with Daniel 3:52-6 at Vespers and Lauds

C. Z $\varepsilon-\varepsilon$ mlakiy $\varepsilon$ ('of Deus meus') sung with Ps 62 [63] at Matins and Ps 21 [22] at Lenten Sext

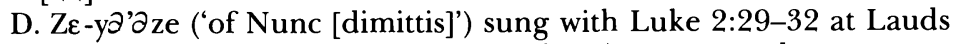

E. Mah'let ('Canticle') sung with Daniel 3:57-88 at Lauds

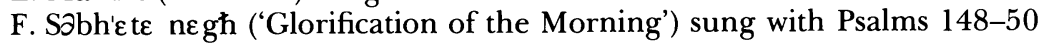
at Lauds

VI. 'Responsorial' chants (collected in a book called $\mathrm{M} \varepsilon$ wa $\$ \partial^{\circ} \mathrm{t}$ )

A. Mrwa\$ $\partial^{\circ} t$ ('Responses') sung before Gospel in morning office on important days and in services for the dead

VII. Chant sung at the end of each office

A. Selam ('Peace')

VIII. Communion chants sung at Mass (collected in a book called Zammare)

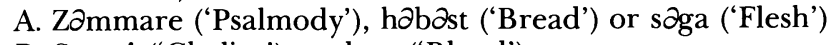

B. S' $\nsim w^{\prime}$ ('Chalice') or dem ('Blood')

C. Menf\&s ('Spirit') 
VII. Chants used during Holy Week to replace improvised liturgical poetry (qene), from the categories of which they take their names:
A. Mibezhu ('Quid multiplicati sunt'), sung with Ps 3 at Matins
B. M $\varepsilon \varepsilon \varepsilon d d \partial s$, named for Sunday Matins when it is sung
C. Kwəllak $\partial \mathrm{mu}$, a short $\mathrm{M \varepsilon} \boldsymbol{w} \varepsilon \mathrm{dd} \partial \mathrm{s}$

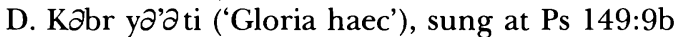
E. 'at'an $\varepsilon$ moger ('toss of incense')

they are not mutually exclusive: some overlap with others, some are subdivisions of larger and more varied categories, and some are called by different names in different manuscripts or in different liturgical circumstances. The liturgical characteristics of the various categories are not the subject of this paper; they are summarised in Table 3 and will be discussed at length in a forthcoming book. ${ }^{34}$ When only musical characteristics are considered, however, many of the two dozen categories of portions can be classified into one of two groups, which I have labelled 'Type I' and 'Type II', as shown in Table 4. Those that belong to neither type are grouped artificially under 'III'.

The earliest manuscripts in our list are devoted to collections of individual categories of portions rather than to the complete D $\partial g$ gwa repertory. There were two possible ways of organising such a collection: either by melodic group, somewhat as in a Western tonary, or according to the days and times when the portions are sung over the course of the liturgical year. Thus both $13 \mathrm{~A}$ and $15 \mathrm{~A}$ are collections restricted to the $\varepsilon r b a^{e} t$ category, but the former is arranged by melodic group, while the latter is in liturgical order. $14 \mathrm{~A}$ contains chants of several categories closely related to the mezmur, arranged by liturgical year. 15B contains fragmentary collections of about ten different categories, brought together into a single disordered volume. Some of its collections have the melodic arrangement, others the liturgical one. Only with $15 \mathrm{C}$ do we have for the first time a true $D \partial g g w a$, with all the chant texts of almost all categories arranged according to the liturgical year, comparable to the Western antiphoner or the Eastern tropologion. The Daggwa has remained the most important type of chant book down to the present, though its contents naturally continued to develop and

34 Shelemay and Jeffery, Ethiopian Christian Liturgical Chant. 
Table 4 Categories of Ethiopian chant portions, arranged by 'type'

I. 'Type I' portions: utilising a system of 'melodic models'

1. $\varepsilon$ rba ${ }^{2} \mathrm{t}$

2. Eryam

3. $\$ \varepsilon l \varepsilon s t$

II. 'Type II' portions: with standardised melodic incipits organised into a system of betoch or 'houses'

A. 'Type IIA' portions: usually preceded by one or more repetitions of the word 'halleluya' sung to standard melismas

1. mezmur

2. $\varepsilon$ bun

3. masbak

4. wazema

5. $\varepsilon$ ng $\varepsilon$ rgari or malt'an

6. $\partial \mathrm{zl}$

7. selam

8. $m \varepsilon n f \varepsilon s$

B. 'Type IIB' portions: preceded by the refrain of Ps 135 [136], 'For his mercy endures forever', sung to standard melismas

1. $\partial \mathrm{sm} \varepsilon \mathrm{l} \varepsilon$-'al $\varepsilon \mathrm{m}$

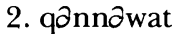

3. zommare

C. 'Type IIC' portions: sung at communion at Mass, with the verse 'For nothing is impossible with God' (Luke 1:37)

1. s'zwa'

III. 'Neither Type I nor Type II'

A. Categories for which there are collections in 15B

1. yatbare k

2. $z \varepsilon-\varepsilon$ mlakiy $\varepsilon$

3. sabh' $\mathrm{at} \varepsilon$ n $\varepsilon$ gh

4. $m \varepsilon$ wa $\$ \partial^{\circ} t$

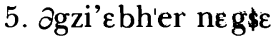

B. Categories for which there are no early collections independent of complete Daggwa MSS

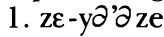
2. mah'let

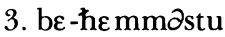
4. mibe zhu
5. mewedd $\partial s$
6. kwallak $\partial \mathrm{mu}$

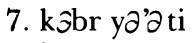
8. 'at'ane moger 
Oral and written transmission in Ethiopian Christian chant

change. In the eighteenth century it became normal to omit the chants for Lent from the complete Daggwa, collecting them instead

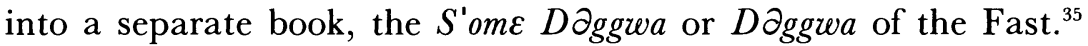
But Lent was already omitted from some earlier sources, for instance our 17A. The tendency to put the Lenten material in a separate book may have been encouraged by the fact that another season, Estemh $\partial r o$ ('teaching'), expanded considerably during the seventeenth century, partly by reduplicating portions borrowed from Lent. Some categories of chant, notably the mewas $\partial^{\mathrm{e}} t$ (responses), zammare (psalmody) and certain categories of liturgical poetry, continued to be transmitted in collections that were inde-

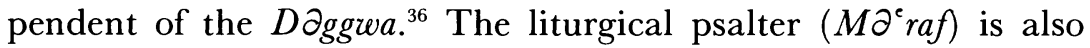
a separate book; its original core, the psalms arranged and notated for chanting in the liturgy, has attracted some other material used for training the singers. ${ }^{37}$ Although manuscripts of the Doggwa and other collections continue to be copied on parchment even in the twentieth century, as an essential part of the training of Ethiopian singers ${ }^{38}$ printed chant books began to appear in the 1960 s, most of them facsimiles of manuscripts copied in the 1940s and 1950s. The sources 20D, 20E, 20F and 20G in Table 2 fit into this category; both the date of printing and the date of the writing of the original manuscript (where known) are given in the Table. ${ }^{39}$

38

Sergew Hable Selassie, interesting list showing the amount of time taken to copy the various liturgical and chant books; a Daggwa takes eighteen months. R. Curzon, who visited an Ethiopian monastery in Egypt in 1833, described traditional copying practices and published a sketch of the monastery library: Visits to Monasteries in the Levant, 5th edn (London, 1865, repr. with an introduction by J. J. Norwich, London, 1983), pp. 134-42. He reported, probably with some exaggeration, that 'One page is a good day's work' (p. 140). See also Velat, 'Chantres, poètes, professeurs'.

39 Unless otherwise specified, dates in these articles are given according to the Gregorian calendar as used in North America and western Europe. The calendar followed in Ethiopia, which derives ultimately from the calendar of Pharaonic Egypt, is seven years behind the Gregorian from 11 September to 31 December, and eight years behind for the remainder of the year (E. Ullendorff, The Ethiopians: an Introduction to Country and People, 3rd edn (London, 1973), p. 177). 
Table 5 The history of Ethiopian chant: a chronological summary

$\mathrm{VI}^{\mathrm{a}}$ : Traditional date of the reign of Gebre Mesqel (558-84), and of the life and work of St Yared

IX: Possible correct date of St Yared (G. Haile, 'A New Look' (see note 4$)$, pp. 318-19)

XIII: Earliest extant written collections of Ethiopian chant texts, with each category collected independently (= 'Type I' Stage I; 'Type II' Stage I) $13 \mathrm{~A}, 14 \mathrm{~A}, 15 \mathrm{~A}, 15 \mathrm{~B}$

$\mathrm{XV}$ : One portion chosen as representative of each 'Type I' melodic group (= 'Type I' Stage II) - 15A, 15B

Earliest extant Daggwa, containing chants of almost all categories in liturgical order, all three 'modes' identified by name - 15C

XVI: Marginal signs for the 'houses' (i.e. the standard incipits of 'Type II' portions) begin to be written by the original scribe in Daggwa MSS (= 'Type II' Stage II) - 16B

Activity of Gera and Ragu'el, who invented or codified the malôkkat

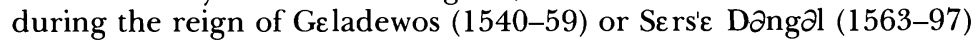

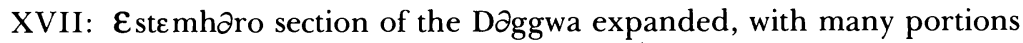
borrowed from the period of Lent (S'om) - 17A

Written lists of the model melodies of 'Type I' portions compiled

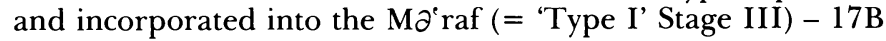

Written lists of halleluya formulas, linked to their respective houses and supplied with music notation, appear in Daggwa MSS (= 'Type II' Stage III) $-17 \mathrm{C}$

XVIII: Portions assigned to Lent now generally collected in a separate book (S'ome Daggwa) - 18A, 18E

XIX: Late in the century, beginning of attempts to notate in greater detail by using more signs $-19 \mathrm{C}$

XX: Printed editions of the Daggwa and other chant books (actually facsimiles of recent MSS) published - 20D, 20E, 20F, 20G

A list of the marginal signs representing the betoch published in 20D

\footnotetext{
${ }^{\mathrm{a}}$ Roman numerals denote centuries.
} 
Oral and written Transmission in Ethiopian Christian chant

The 'Type I' portions. The Type I group includes three categories, the $\varepsilon r b a^{e} t$, Eryam and belest. Each is distinct from the other two in terms of textual form, melodic content and liturgical function. Yet all three have a similar history, which is included in the chronology in Table 5. 13A is a collection of one of these three categories, the $\varepsilon r b a^{e} t$, representing what I call 'Stage I'. In 13A we find the texts arranged according to their melodic groups, that is to say they are grouped with other texts sung to similar melodies, each group headed by the rubric bezemahu ('in its [own] melody'), zehime bezemahu ('this also in its [own] melody'), or sareyu (the meaning of this term will be discussed below). Within each melodic group the texts are arranged in the order of the liturgical year. 15B includes, among other things, collections of texts belonging to all three categories of Type I, arranged by melodic group as in 13A. In Figure 3 we can see, after the third line of text, a line indicating the beginning of a new melodic group. After that line is the rubric 'This also in its own melody', meaning that all the texts that follow belong to the same melody, or rather melodic family. The individual portions of the group follow, arranged in the liturgical order of their feasts, separated from each other by rubrics and by obeli or 'daggers' in the margin. There has, however, been a new development, 'Stage II'. In each melodic group in 15B, one portion has been singled out to serve as representative of the entire group; its name is written in the top margin of the page the group begins on, apparently in the hand of the original scribe. The incipit of the group representative, which in Figure 3 is 'On this day', is followed by the words 'in which one would say', meaning that the melody of 'On this day' serves as the typical one for this entire group of portions. Sometimes the first chant in the group (i.e. the one that appears earliest in the liturgical year) was chosen arbitrarily to represent the entire group. But in other cases, as in Figure 3, a chant from elsewhere in the group was chosen, evidently because it was somehow considered a more appropriate representative of the group as a whole. These group representatives were dubbed 'melodic models' ('modèles mélodiques') by Velat. ${ }^{40}$ We continue to use this term until such time as a more profound understanding of them may suggest a more appropriate one. 
name of 'melodic model'

written in upper margin

(translation:) 'On this day' [is

the model] in which one would

say [the following portions]
line separates melodic groups

(translation:) This [group] also

in its own melody [i.e., 'On this day']

'daggers' separate individual portions, arranged in liturgical order, each beginning with a rubric identifying its feast

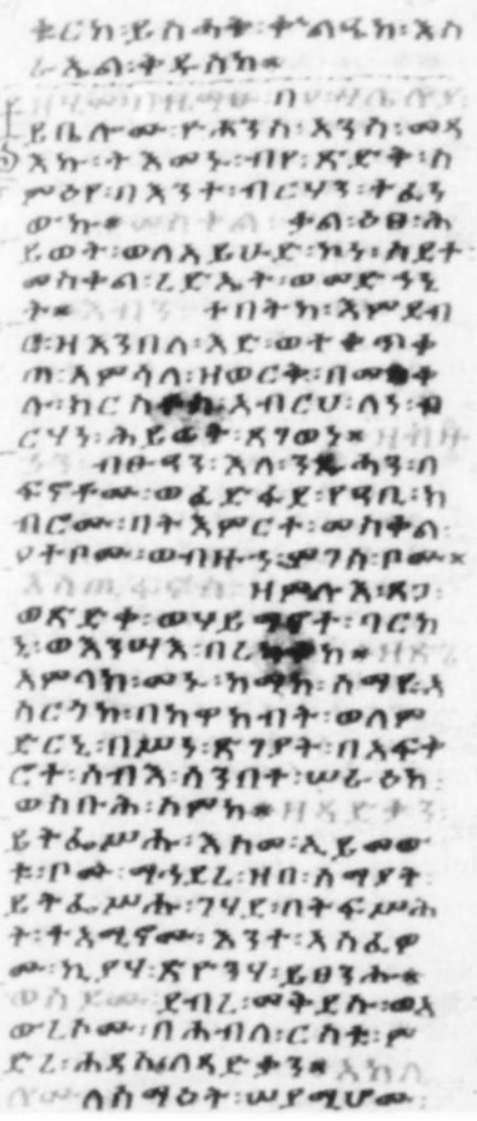

Figure 3 15B, fol. 10a, col. 2

Already in $15 \mathrm{~A}$, in which the $\varepsilon r b a^{e} t$ portions are arranged according to the liturgical year, each text is preceded by the text incipit of its group representative or 'melodic model', written in red. The page shown in Figure 4 contains chants for the feast of the archangel Gabriel, each portion separated by a line. But each is preceded by a rubric indicating its melodic group. The three melodic groups shown here, 'On this day', 'John cried out' and 'At that time it was Sabbath' are each followed by the traditional formula 'in which one would say'. The practice of giving the name 
Oral and written transmission in Ethiopian Christian chant

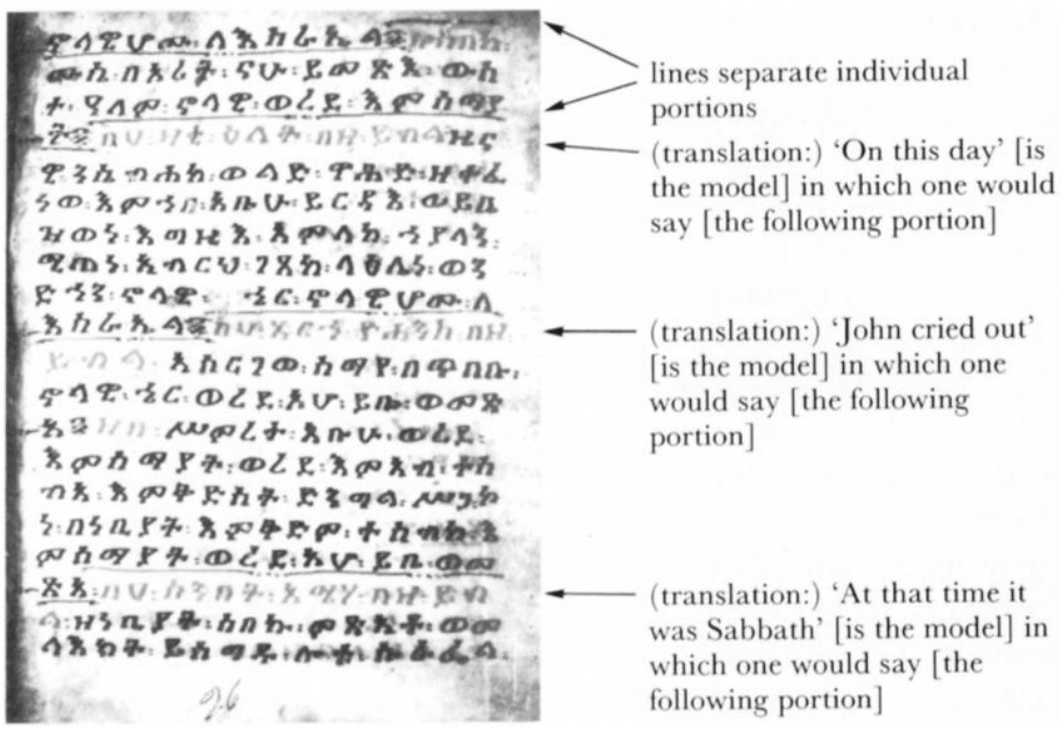

Figure 4 15A, fol. 26a, feast of the archangel Gabriel

of the melodic model in red before every text in the same group was continued in $15 \mathrm{C}$, our earliest Daggwa, and in all other Daggwa manuscripts down to the present. It is interesting that the second model, 'John cried out', does not occur in more recent sources; its group has either disappeared or adopted a different portion for its model.

The practice of preceding a text with the name of a melody - a name derived from the incipit of a different text deemed the 'model' - will inevitably remind chant scholars of the Byzantine heirmos or the Syriac resh qala. As will be shown below, however, the relationship between an Ethiopian 'model' and its 'derivative' can be much looser, with much of the resemblance concentrated towards the beginning. The full range of possible relationships will not be known until there have been exhaustive studies comparing selected models with their complete 'family' of derivatives.

In 'Stage III' the texts of the melodic models themselves were being assembled into written lists. By the seventeenth century these lists were beginning to be written down and incorporated into an emerging type of liturgical book known as the $M \partial^{\mathrm{e}} \mathrm{raf}$ ('sections' or 'stopping-places'), which primarily contains texts of the psalms pointed and notated for liturgical chanting. Our MS 
17B appears to be one of the earliest examples. ${ }^{41}$ The primarily oral character of these lists is still evident, however. Boys training to be ecclesiastical singers work at memorising both the texts and their melodies during the night when it is impossible to read. For this reason the lists, along with certain other material to be mem-

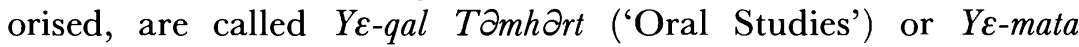
Tamh $\partial r t$ ('Night Studies'). ${ }^{42}$

The 'Type II' portions. A much greater variety of categories makes up what I call Type II, listed in Table 4. It subdivides into further groups on the basis of a simple difference in performance practice. The categories of Type IIA, the first three of which are partly interchangeable, are usually preceded by the word 'halleluya', sung from one to ten times according to standard melodic formulas. The categories of Type IIB are preceded instead by one

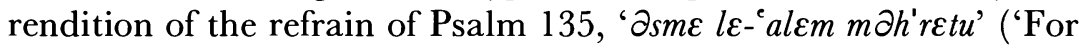
his mercy endures forever'). Type IIC includes one of the three types of communion hymns. It is preceded by the Gospel verse 'For nothing is impossible with God' (Luke 1:37), apparently referring to the miraculous transsubstantiation of the eucharistic bread and wine.

The earliest collection of Type II portions, 14A, is arranged by liturgical year. It seems to show that the various subcategories of this type were perhaps not fully differentiated. On every feast there is a series of chant texts, including some that later manuscripts would assign to the mezmur or $\varepsilon b u n$ categories, others that would later be assigned to the $\partial s m \varepsilon l \varepsilon$ - $^{-}$alsm category, and sometimes a few that would later belong to other Type II categories. Rubrics indicating the category are rare in this manuscript, and there are no markings of any kind to separate the mezmur texts from the $\partial s m \varepsilon$ $l \varepsilon$ - $^{-} a l \varepsilon m$ ones, which in any case are often intermingled. One can often recognise a mezmur or $\varepsilon b u n$ text because it will be preceded by a numeral indicating the number of times the word 'halleluya'

41 Berlin, Staatsbibliothek Preussischer Kulturbesitz, MS orient. oct. 1268 (= Hs. 40 in the catalogue of E. Hammerschmidt and V. Six, Äthiopische Handschriften, I: Die Handschriften der Staatsbibliothek Preussischer Kulturbesitz, Verzeichnis der orientalischen Handschriften in Deutschland, xx/4 (Wiesbaden, 1983)), is a MS dating 1563-97 that includes a $M \partial r$ raf, but Hammerschmidt and Six do not say whether the contents include the melodic models. On the palaeography see Uhlig, Äthiopische Paläographie, p. 462.

42 These texts are edited without notation in Velat, Me eräf, pp. 34-68, and are translated and discussed in Velat, Études sur le Méeräf, pp. 218-66. 
should be sung at the beginning, but this does not mean that any text lacking such a number must be an $\partial s m \varepsilon l \varepsilon$ - $^{-} a l \varepsilon m$. In a few places wazema and ' $\partial z l$ texts are clearly designated as such by a rubric (e.g. fol. 48a), but in other places they are not. The one type of category that seems to be consistently identified in the manuscript is the $q \partial n n \partial w a t$, which always comes at the very end of the series of chants assigned to each feast. In later sources of

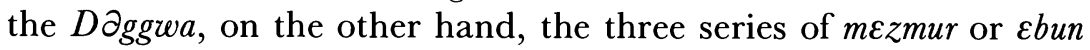
texts, $\partial s m \varepsilon l \varepsilon$ - ${ }^{-} a l \varepsilon m$ texts and $q \partial n n \partial w a t$ texts will be fully segregated from each other, with each series clearly identified by a rubric at the beginning.

For two categories of Type IIA portions, selam and wazema, substantial remnants of collections survive in $15 \mathrm{~B}$, both of which are organised by liturgical year. These, together with 14A, represent 'Stage I' in the history of Type II, corresponding to Stage I in the history of Type I. In 15C we find the texts of all the Type IIa

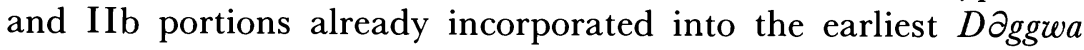
manuscript. Since then they have remained among the normal contents of the Doggwa, though separate collections of individual categories did not die out completely. ${ }^{43}$

At some unknown time, however, Type II chants also came to be understood as belonging to groupings known as betoch or 'houses'. Portions belong to the same house when they have the same melodic incipit; the house itself came to be named for the textual incipit of a representative chant from the group. 'Stage II' took place when these houses began to be designated by written signs, each appearing in the margin next to the first line of the portion to which it applied. The earliest appearance of such signs is in the selam collection in $15 \mathrm{~B}$, in a hand different from that of the original scribe but nevertheless belonging to the fifteenth century. But, as can be seen in Figure 5, the written system had not yet been stand-

43 See our sources 20C, which includes a collection of $m \varepsilon z m u r$, and 20G, which includes collections of $m \varepsilon z m u r$ and $\partial s m \varepsilon l \varepsilon-{ }^{\circ} a l \varepsilon m$. The nineteenth-century source Paris, Bibliothèque Nationale, MS d'Abbadie 87 contains collections of: mezmur (fols. la-68b), selam and wazema (69a-92b, though the rubric on $69 \mathrm{a}$ speaks of selam and mezmur), wazema

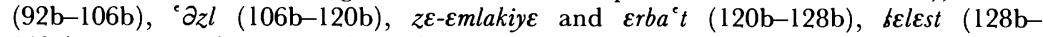

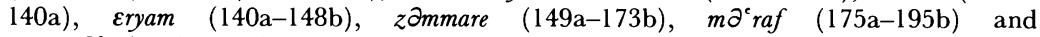
$m \varepsilon w a \partial^{e} t(195 \mathrm{~b}-209 \mathrm{a})$. This description is more accurate than the ones in C. Conti Rossini, 'Notice sur les manuscrits éthiopiens de la collection d'Abbadie', Joumal Asiatique (Nov-Dec 1912), pp. 469-70, or M. Chaîne, Bibliothèque nationale: catalogue des manuscrits éthiopiens de la collection Antoine d'Abbadie (Paris, 1912). 
Kay Kaufman Shelemay, Peter Jeffery, Ingrid Monson

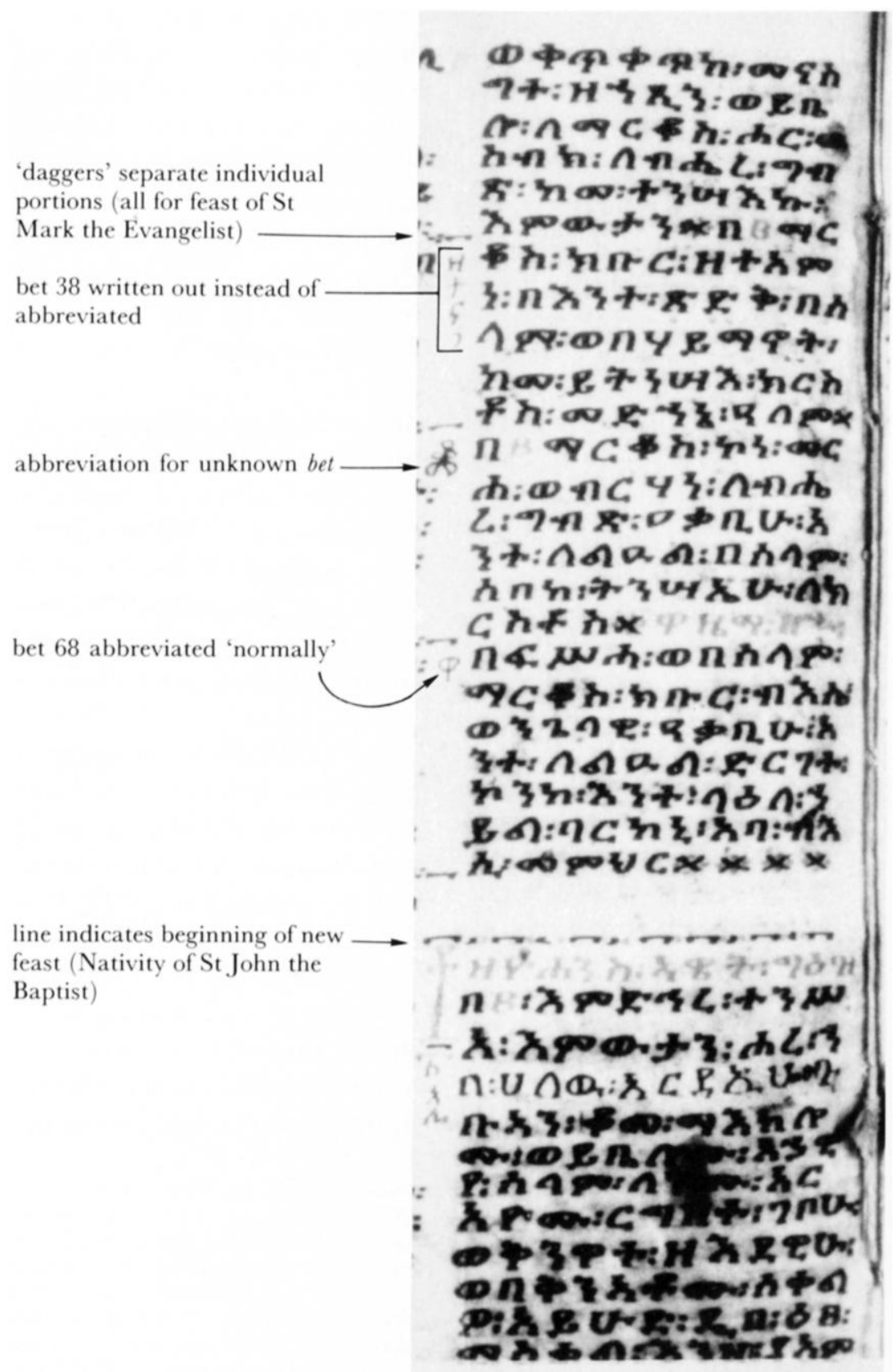

Figure 5 15B, fol. 126b, col. 2 
ardised. The first bet sign, B38 in our list, is completely written out except for its final letter - though it was this final letter that became the standard abbreviation in later sources. The second bet sign is an abbreviation of some sort (it consists of the letter qo written over the letter $m \varepsilon$ ), but it cannot be identified with any bet known to us from twentieth-century sources of information. ${ }^{44}$ On the other hand the third bet sign, B68 in our list, is already the one that became standard, the first letter of the complete word. The earliest source in which bet signs according to the standard system appear to have been written by the original scribe is $16 \mathrm{~B}$, but the majority of such signs even in this manuscript were clearly added by later hands.

The practice of classifying chants by melodic incipit is of course known also in medieval western Europe, where it competed with that of classifying melodies according to their final. ${ }^{45}$ As Monson's discussion below indicates, the notion of 'final' is much less central in Ethiopian chant, though not completely absent. It is in any case quite useless for distinguishing the Ethiopian 'modes'. The bet system, on the other hand, is one of several indications that in Ethiopia it is the beginnings of melodies that are particularly important.

At some point the standard incipits of the bet system became linked to the standard melodic formulas with which the words 'halleluya' and 'For his mercy endures forever' were sung with each Type II portion. This was only natural, for in performance these prefatory formulas would have been followed immediately by the beginning of the portion itself. In Stage III, written lists of these 'halleluya' and 'For his mercy' formulas, supplied with musical notation, began to be drawn up, with each formula attached to its textual bet incipit, also with musical notation. Such a list is called EnqEs' $\varepsilon$ Halleta ('The gate of the halleluya material'), but because each halleluya or refrain melody is linked to a bet it also serves as a list of bet and a guide to the bet system as a whole. The earliest manuscript in our list of sources to include such a halleluya list is

44 Bet 23 in our list, $\varepsilon l s^{\prime} i q o$, is normally abbreviated $q o$, but there is no $m \varepsilon$ in this word. The G $\partial^{\circ} \partial \mathrm{z}$ word qome ('stop'), written exactly as shown in Figure 5, can be found in the margins of biblical manuscripts, where it signals the end of a pericope or liturgical reading (R. Zuurmond, Research into the Text of the Synoptic Gospels in $G e^{e} e z$, II (Delft and Faringdon, Oxon., 1987), p. 48; Uhlig, Äthiopische Paläographie, pp. 91-2.

45 M. Huglo, Les tonaires: inventaire, analyse, comparaison (Paris, 1971), pp. 72, 399-412. 
Kay Kaufman Shelemay, Peter Jeffery, Ingrid Monson

$17 \mathrm{C}$, though a slightly earlier manuscript dates from A.D. $1667-8{ }^{46}$ The list in $17 \mathrm{C}$ is already very similar to the Enqes' $\varepsilon$ Halleta lists normally found in Daggwa manuscripts from that time on. Not until printed books appear in the 1960s, however, do we find lists of the bet signs, giving all the marginal abbreviations according to 'mode' and identifying each with its fully spelled-out bet. This final development is 'Stage IV'. There are 123 bet signs in the list in $20 \mathrm{D}$, but our chief informant evidently regarded some of them as duplications, for he sang only 114 .

While we have not yet identified the sources of many of the betoch, it appears that they tend to be derived from portions of the

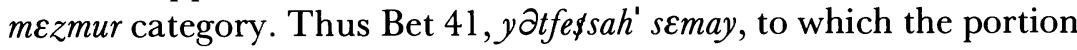
in our Figure 2 belongs, derives from the mezmur from the morning

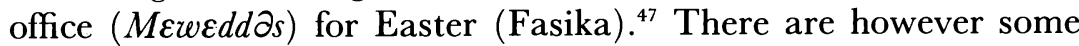
exceptions. Bet 68 , wazema, is used for many portions of the wazema category; its source may be the wazema of the feast of the Four Heavenly Creatures, $8 \mathrm{H} \partial \mathrm{dar} .{ }^{48}$ Bet 97.3 , engergari, which appears to duplicate Bet 91, qum हngergari, seems to be used for the engergari or malt'an category in general and not to have a specific source in one particular portion. But there is at least one example of a sclam in this bet, sung at the end of the wazema (Vespers) office on

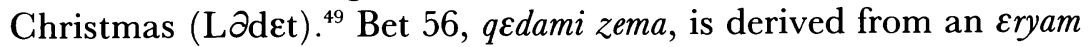
for Easter (Fasika), ${ }^{50}$ even though the portions of the Eryam category do not participate in the bet system.

The written history of the 'modes'. As explained above, all Ethiopian chants are assigned to one of three groupings that Westerners like to call 'modes', though in Ethiopic each grouping is called an 'order' (solt) or 'chant' (zema). ${ }^{51}$ Traditionally these three zemat are attributed to St Yared. But they may have emerged more recently, and there may once have been only two modal classifications. The

46 Uppsala, Universitetsbiblioteket, MS O Ethiop. 36, described in Löfgren, Katalog, pp. 67-75. EMML 3890, which also contains an Enqes' $\varepsilon$ Halleta, is of about the same date as our $17 \mathrm{C}, 1693-1716$.

47 In our source $20 \mathrm{D}$, it is located on p. 249, col. 1, line 16 .

48 20D, p. 86, col. 1 , line 23 .

$4920 \mathrm{D}$, p. 196, col. 1, line 25.

so 20D, p. 249, col. 1, line 1 .

51 The word zema, however, can also be used as the general term for the chant of the Ethiopian Orthodox Church. See K. K. Shelemay, Music, Ritual, and Falasha History (East Lansing, MI, 1986), pp. 99-101. 
Oral and written transmission in Ethiopian Christian chant

three modes $g \partial^{e} \partial z$, ' $\partial z l$ and Eraray are all named in $15 \mathrm{C}$. But earlier sources seem to know only $g \partial^{c} \partial z$ and ${ }^{c} \partial z l$, as if there were a time when only these two modes were in use. These sources include 14A, the selam collection in $15 \mathrm{~B}$ and the early Z2mmare EMML 2091 of the fifteenth or sixteenth century. The Mestegab' $\partial$, a selection of psalm verses memorised by boys in training as part of the Night Studies, also includes only $g \partial^{`} \partial z$ and ${ }^{e} \partial z l$ sections, though we do not know when this collection was assembled. The collections of Type I chants in 13A and 15B name none of the modes, but identify some melodic groups as being 'in the second zema' $\left(\right.$ be-kald' zema) as if there were then only two zemat. ${ }^{52}$ The possibility that there may once have been only two modes suggests an explanation for the names $g \partial^{c} \partial z$ and ' $\partial z l$, which can be translated 'common' and 'apart' or 'special'. ${ }^{53}$ The 'special' character of ' $\partial z l$ may be connected with the fact that it is associated with particular seasons of the year. ${ }^{54}$ Perhaps, then, there were originally only two modes, one used generally, the other restricted to certain special occasions. The name eraray, thought to be an Amharic onomatopoeic term for crying in a high or loud voice, ${ }^{55}$ may have arisen at a later time to designate the higher-range chants of the ' $\partial z l$ group. Support for this view may be found in Monson's observation, reported below, that there are only two 'background pitch sets', one for $g \partial^{e} \partial z$, the other for ' $\partial z l$ and Eraray. This hypothesis needs to be confirmed by extensive investigation of the history of the modal designations and notations of portions now assigned to eraray. In any case, three modes with the modern names already existed at the time $15 \mathrm{C}$ was copied. ${ }^{56}$

52 On the other hand, an alternative interpretation is suggested by the selam and wazema collection in Paris MS d'Abbadie 87 (19th century). It is organised into $g \partial^{\circ} \partial z$ (fol. $69 \mathrm{a})$, bekal $\partial$ ' zema (77a), Eraray (80a) and ' $\partial z l(89 \mathrm{~b})$, suggesting that the 'second zema' is here regarded as a subdivision within $g \partial^{\circ} \partial z$.

53 Cf. Dillmann, Lexicon linguae aethiopicae, p. 1189 . For more on the terminology, see Shelemay, Music, Ritual, and Falasha History, pp. 168-73.

54 See the treatise in Vatican MS Aeth. 245, fol. 10a; the opening is translated into Latin in Grébaut and Tisserant, Codices aethiopici, p. 755. For some other theoretical literature on the modes see E. Cerulli, I manoscritti etiopici della Chester Beatty Library in Dublino, Atti della Accademia Nazionale dei Lincei, Classe di Scienze Morali, Storiche e Filologiche, 8th series, xI (1965), p. 300 (a MS of the seventeenth or eighteenth century), EMML 3434, fol. 114a (eighteenth century), our source 19D (EMML 2936).

${ }_{55}$ W. Leslau, Comparative Dictionary of $G \partial^{\circ} \partial z$ (Classical Ethiopic) (Wiesbaden, 1987), p. 39.

56 Cerulli, La letteratura etiopica, p. 163, asserts that a late seventeenth-century revision of the Daggwa, prepared by Qale Ewadi at Debre Libanos, was especially concerned with the modes of the chant; but he cites no sources and we have no further information. 
The development of the notation. Ethiopian traditions seem to say that the notation was invented by two priests, Gera and Ragu'el, who are said to have lived at some time during the sixteenth century. ${ }^{57}$ The manuscript evidence is more or less consistent with this. Fifteenth-century manuscripts lack music notation altogether. The scribes who copied 16B and 16C evidently did not foresee the addition of notation, although it was added over some of their texts during the seventeenth century. ${ }^{58}$ But in $16 \mathrm{D}$ and all subsequent manuscripts, the original scribe left space for the notation above each line of text, and this notation was actually entered during the copying of the text or shortly afterwards. The notation of 16A (late fifteenth or early sixteenth century) stands apart from that of all other known sources, however, and makes it an important manuscript for investigating the origins of the notation. Most of its $m \partial l \partial k k \partial t$ are not much later than the text itself, but they and especially the $y \varepsilon f i d \varepsilon l q \partial r s^{\prime}$ are notably more sparse than in other sources. The notator rarely bothered to indicate $\varepsilon n b \partial r$ at the ends of portions, for instance, and he wrote other signs very sparingly compared with later manuscripts. Indeed, in not a few places additional signs have been put in by scribes of later periods. A number of features confirm the impression that $16 \mathrm{~A}$ witnesses to an early stage when the notational system was not yet fully developed. The yefidel $q \partial \mathrm{rs}^{\prime}$ are especially sparse: $d \partial f a t$ occurs very rarely, while $d \varepsilon r \varepsilon t, r \partial k r \partial k$ and $h \partial d \varepsilon t$ seem not to have been used at all by the original notator. On the other hand, there are frequent vertical or slanted strokes both within and above the texts, which appear to have been deliberately intended to convey declamational information of some sort. Their frequency, combined with the limited use of the conventional signs, seem to indicate that this manuscript was notated at a time when the $m \partial l \partial k k \partial t$ system had already developed but the $y \varepsilon f i d \varepsilon l q \partial r s^{\prime}$ system was still being worked out.

The historical development of the $y \varepsilon f i d \varepsilon l$ q $\partial s^{\prime}$ and the $m \partial l \partial k k \partial t$ as written systems can be traced by following a single portion all the way through our series of dated manuscripts. Through such study one can learn much about the notational history of the chant.

57 See discussion in note 29.

58 Because most of the $m \partial l \partial k k \partial t$ are characters from the syllabary, they can be dated by the same palaeographical techniques used for dating Ethiopian texts; see Uhlig, Äthiopische Paläographie, pp. 539-40. However, the dating of scripts from before the seventeenth century is still difficult because dated landmarks are so rare. 
Oral and written transmission in Ethiopian Christian chant

Our Table 6 compares the notation of the first portion in the Daggwa (the one illustrated above by Shelemay) as it occurs in all the notated sources on our list in Table $2 .^{59}$ The text is given beneath the notation of 20D, because this is the source our informant used to perform the portion. We begin with the rubric indicating the category of the chant (molt'an in most manuscripts, wazema or mezmur in some) and its assignment to the feast of St John the Baptist (1 Meskerem), the first day of the liturgical year. Then, most sources give the abbreviation for the bet, which is B41 in our list. After that, the indication 'in 1' means that the word 'halleluya' is sung once. Thereafter, the numbers preceded by a capital G represent $m \partial l \partial k k \partial t$ in the $g \partial^{c} \partial z$ mode for which we have transcriptions. An asterisk after the number means that this particular place is the source ( $s \partial r \varepsilon y u)$ of the melodic formula associated with this $m \partial l \partial k k \partial t$. The underlined syllables are transliterations of $m \partial l \partial k k \partial t$ for which we have no musical transcriptions, because our informant did not include them in his list. All the other symbols -

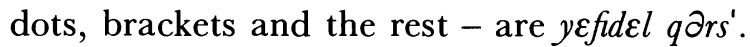

In the very earliest sources, the notation is sometimes inconsistent, as if a great variety of melodic traditions were in circulation. Our example is more consistent than most, perhaps because it is the first portion in the $D \partial g g w a$. $16 \mathrm{D}$ contains an especially large number of variants throughout all the portions we checked, as if it represented a tradition quite different from the one that became more or less standard. The most noteworthy early variant is the very first $m \partial l \partial k k \partial t$ in $16 \mathrm{~B}$, which is the syllable $y u$ for $s \partial r \varepsilon y u$. A modern Ethiopian singer would presumably look to the text below and, seeing the words $b \partial z^{\prime} u^{c} \partial \varepsilon n t \varepsilon$ yoh' $\varepsilon n n \partial s \partial$, decide to sing the melodic formula he has memorised with these words. This would be formula G88 in our dictionary, but one that occurs at this place in no other source. Was it indeed what the scribe who notated 16B actually intended? The problem is complicated by the fact that $b \partial z^{\prime} u^{e} \partial \varepsilon n t \varepsilon y o h ' \varepsilon n n \partial s \partial$, 'Blessed are you John', is a textual formula, beginning a number of portions for this feast day and (with the name changed) many other feasts as well. But almost all of the portions for St John's day that begin with this incipit, in all sources including $16 \mathrm{~B}$, are notated with the same $m \partial l \partial k k \partial t$ as our portion

59 The complete chart will be published in Shelemay and Jeffery, Ethiopian Christian Liturgical Chant. Here we reproduce the chart for only the first two phrases of portion 1. 


\section{Kay Kaufman Shelemay, Peter Jeffery, Ingrid Monson}

\section{Table 6 The first portion in the Daggwa}

\begin{tabular}{|c|c|c|c|c|c|}
\hline$\overline{15 C}$ & & & & & \\
\hline & $1 a, 1,13$ & malt'an & & in 1 ? & 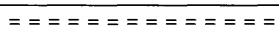 \\
\hline \multicolumn{6}{|l|}{$\overline{16 \mathrm{~A}}$} \\
\hline & la & [first folio faded and illegible] & & & \\
\hline \multicolumn{6}{|l|}{$\overline{16 B}$} \\
\hline & $6 a, 1,29$ & malt'an of John & yo & in 1 & 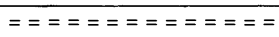 \\
\hline \multicolumn{6}{|l|}{$\overline{16 D}$} \\
\hline & $5 b, 1,1$ & malt'an of the evening & bet 41 & in 1 & 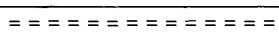 \\
\hline \multicolumn{6}{|l|}{$\overline{17 \mathrm{~A}}$} \\
\hline & la, 1,16 & malt'an of the evening of St John & bet 41 & in 1 & 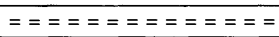 \\
\hline \multicolumn{6}{|c|}{ 1 } \\
\hline & $5 a, 1,21$ & & bet 41 & in 1 & 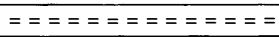 \\
\hline \multicolumn{6}{|r|}{ 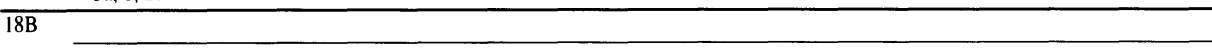 } \\
\hline & $5 \mathrm{a}, 1,12$ & & & in 1 & 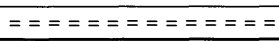 \\
\hline \multicolumn{6}{|r|}{ 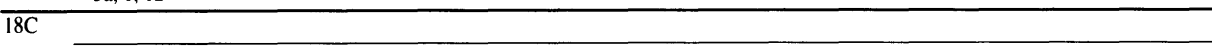 } \\
\hline & $5 \mathrm{a}, 1,1$ & malt'an of the evening & bet 41 & in 1 & 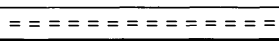 \\
\hline \multicolumn{6}{|r|}{-2} \\
\hline & $3 a, 1,13$ & wezema of John & bet 41 & in 1 & $===+==+==+===$ \\
\hline \multicolumn{6}{|r|}{+2} \\
\hline & $4 a, 1,22$ & mezmur of the evening & bet 41 & in 1 & 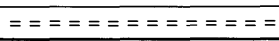 \\
\hline \multicolumn{6}{|r|}{ 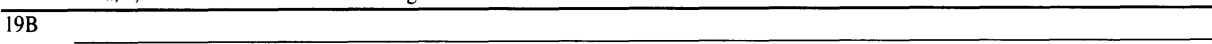 } \\
\hline & $3 a, 1,28$ & malt'an of the evening on 1 Meskerem & bet 41 & in 1 & 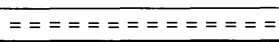 \\
\hline \multicolumn{6}{|c|}{ 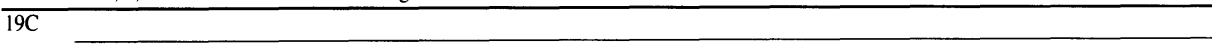 } \\
\hline & $4 a, 1,1$ & molt'an of the evening & & in 1 & 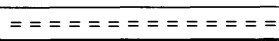 \\
\hline \multicolumn{6}{|l|}{$\overline{20 \mathrm{~A}}$} \\
\hline & $7 \mathrm{a}, 1,19$ & malt'an of the evening on the feast of St John & bet 41 & in 1 & 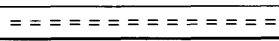 \\
\hline \multicolumn{6}{|l|}{$\overline{20 B}$} \\
\hline & $6 a, 1,20$ & molt'an of the evening of John & bet 41 & in 1 & $====0==+===$ \\
\hline \multicolumn{6}{|l|}{$\overline{20 D}$} \\
\hline & $1,1,10$ & malt'an of the evening of John the Baptist & bet 41 & in 1 & 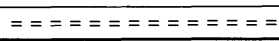 \\
\hline \multicolumn{6}{|c|}{ 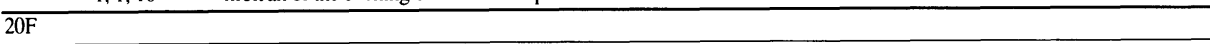 } \\
\hline & $7,1,4$ & & bet 41 & in 1 & 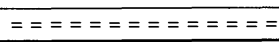 \\
\hline \multirow[t]{3}{*}{$\overline{20 D}$} & & & & & gu'u: \\
\hline & & & & & $g u^{\prime} u:$ \\
\hline & $392,1,28$ & [halleluya table] & bet $41^{*}$ & in 1 & ha- $\quad$ lle \\
\hline
\end{tabular}




\section{Oral and written transmission in Ethiopian Christian chant}

\section{Table 6 continued}

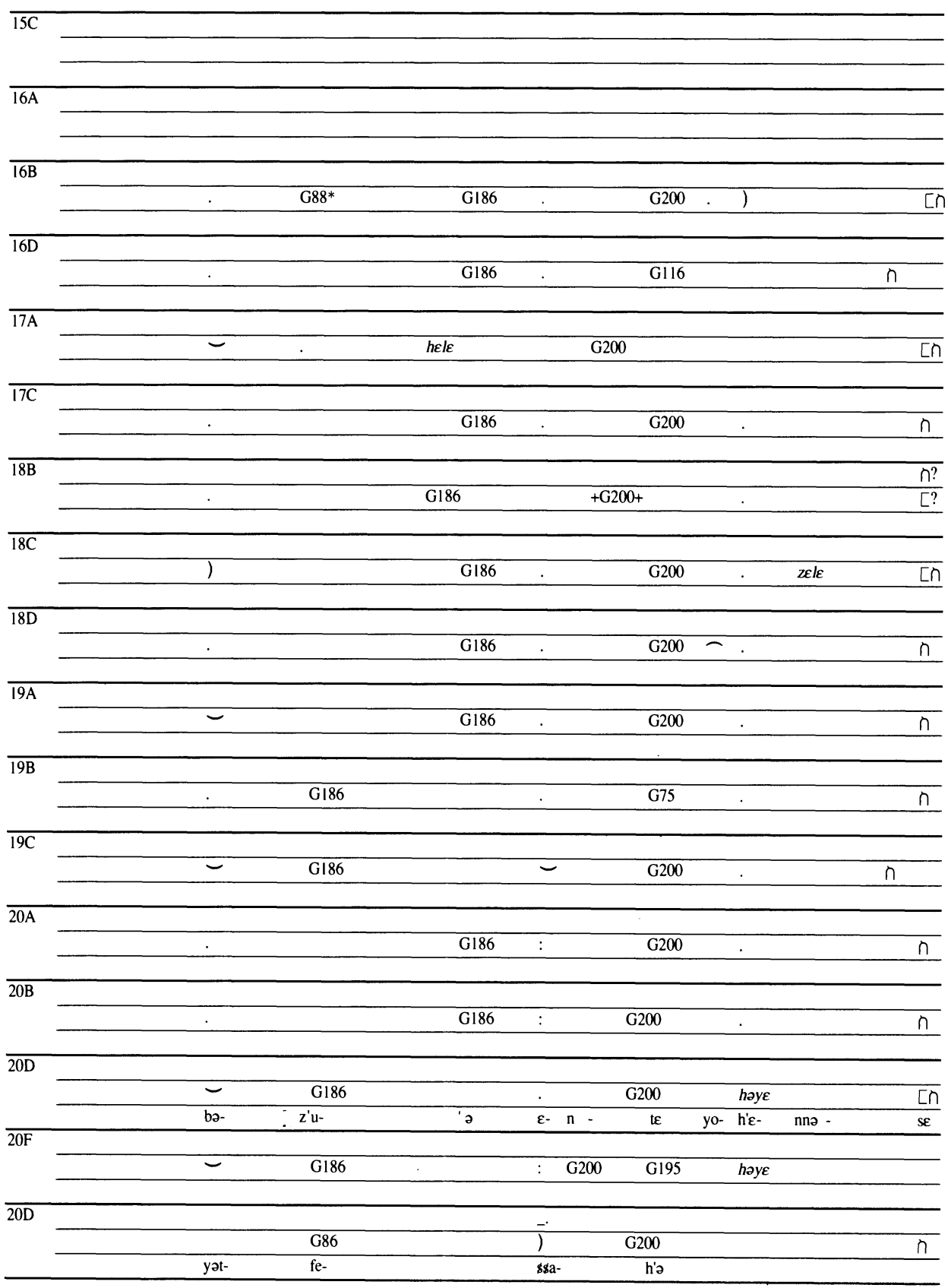




\section{Kay Kaufman Shelemay, Peter Jeffery, Ingrid Monson}

\section{Table 6 continued}

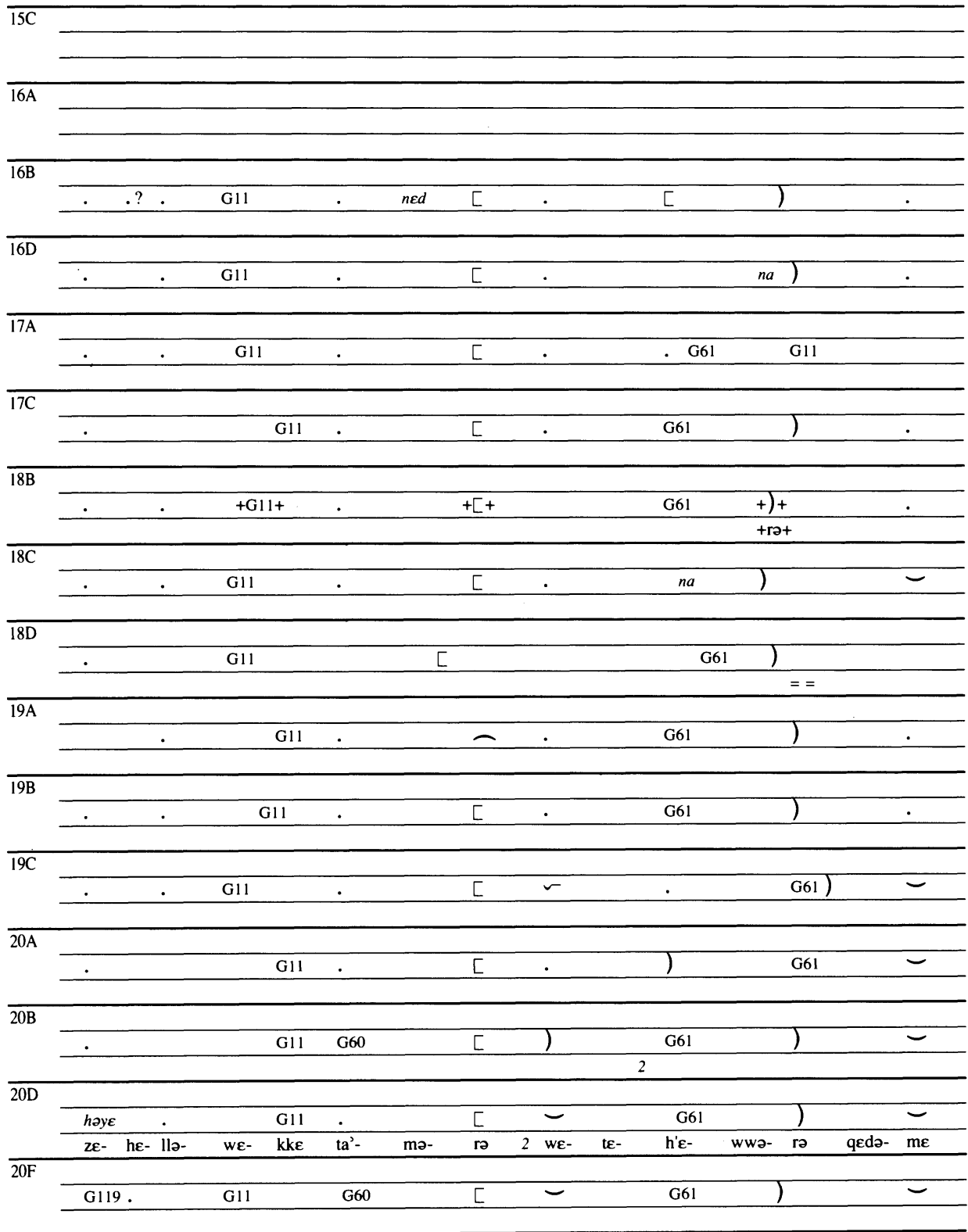


Oral and written transmission in Ethiopian Christian chant

1, namely G186 followed by G200. The source, or sareyu, of G88

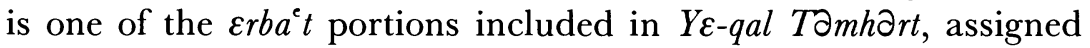
to the following Sunday. ${ }^{60}$

As the chart for portion 1 shows, much of the notation had stabilised by the seventeenth century, except at certain points that for some reason continued to vary over time. At one point in this

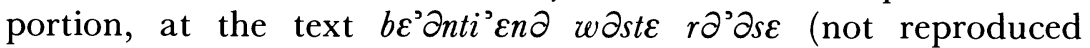
in Table 6), the manuscripts not only differ among themselves, but often contain $m \partial l \partial k k \partial t$ that are not to be found in our list. Once achieved, the overall notational stability lasted through the seventeenth and eighteenth centuries and into the nineteenth. In the late nineteenth and the twentieth centuries, many more signs came to be added to the notation, as if singers were beginning to lose their grip on the tradition, and compensated by attempting to notate as specifically as possible. Our example has experienced less of this than other portions, but on p. 2 it will be noted that the two most recent sources, 20D and 20F, contain $m \partial l \partial k k \partial t$ not found earlier:

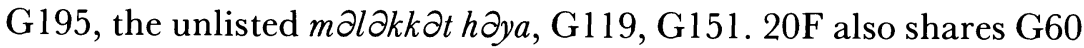
with $20 \mathrm{~B}$.

Once the notation is understood it is possible to seek a better understanding of how the Type I and Type II groups actually function. Table 7 compares the notation of the first melodic model for the Eryam category, portion 12 in our forthcoming anthology, with several other Eryam texts that take the portion 12 melody for their model. Boxes outline places where the melodies agree with portion 12, and it will be readily observed that these are more common towards the beginning of each portion. The use of Al for the final cadence is very common among portions in the eraray mode; its presence in four of our six examples should not be overrated. However, only extensive study will determine how typical portion 12 is of the Ethiopian repertory as a whole.

Table 8 compares a Type IIa portion (our no. 1, the same one as illustrated in Table 6 ) with the portion that serves as the source of its bet (B15), where the notation represents no single source but is conflated from several twentieth-century manuscripts. The two

${ }^{60}$ For the text, see Velat, Me eräf, p. 49 no. 15. For a translation see Velat, Études sur le $M e^{e} e r a \bar{f}$, p. 246 no. 15. For its liturgical assignment (the Sunday after St John's day) see 20D 8, 2, 18. For the $m \partial l \partial k k \partial t$, which have not been published, see EMML 1347, fol. $37 \mathrm{~b}$, col. 1 , line 5 . 
Kay Kaufman Shelemay, Peter Jeffery, Ingrid Monson

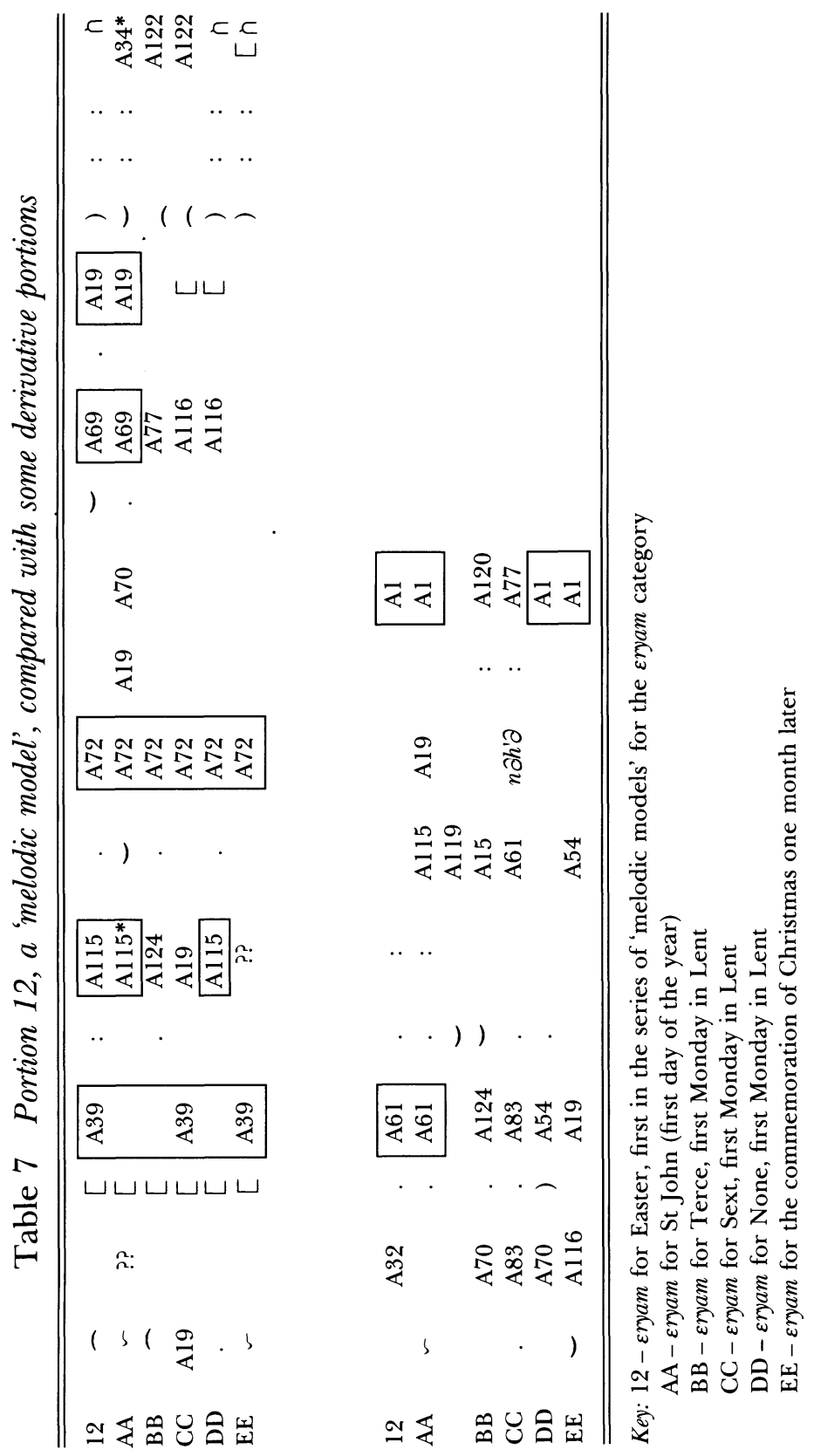


Oral and written transmission in Ethiopian Christian chant

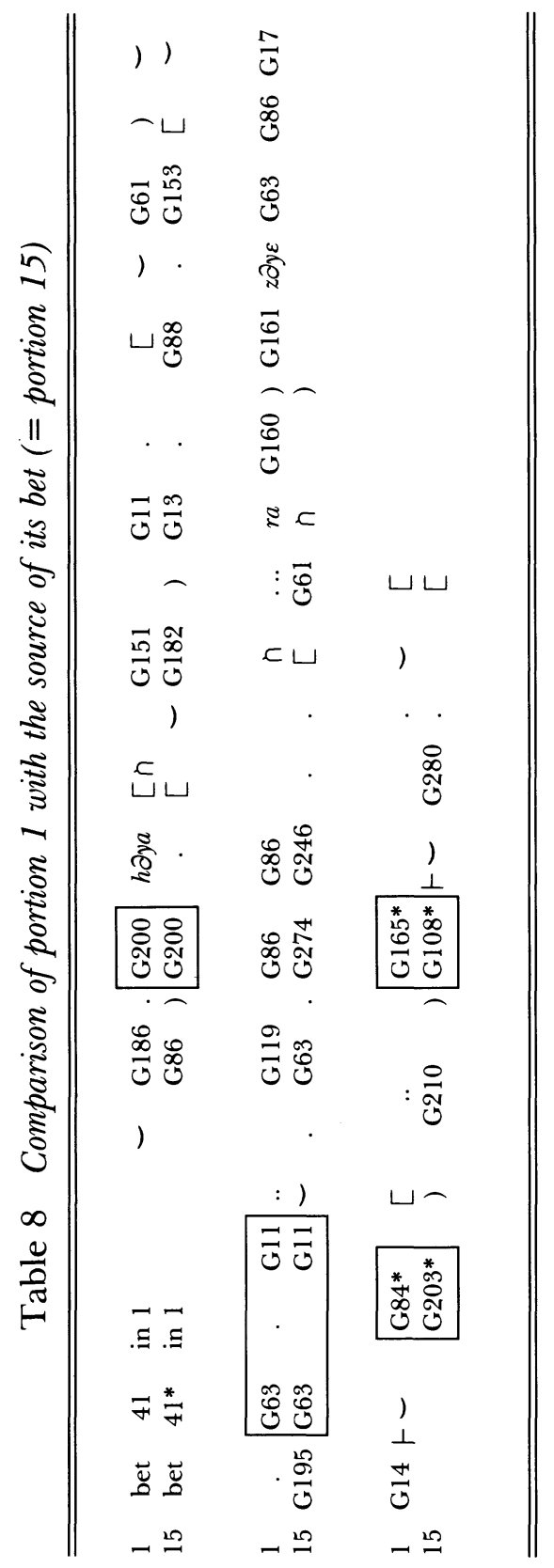


Kay Kaufman Shelemay, Peter Jeffery, Ingrid Monson

have of course the same halleluya melisma, with the word 'halleluya' being sung only once. They agree in having G200 near the beginning, and G63 followed by G11 in the middle of the chant. Interestingly, they also agree in having the sources of two formulas (sareyu) close to the end (note the asterisks), though the two formulas are different in each case. Beyond that there is little similarity. Clearly the relationship between a Type II portion and the source of its bet is even looser than the relationship between a Type I portion and its melodic model. To the very limited degree that we can generalise from these two portions, it would seem that a bet is not a model at all, but governs only the halleluya and (loosely) the incipit. Indeed, comparison of Table 8 with Table 7 suggests that, in Ethiopian chant, similarities tend to cluster near the beginnings of the related portions. There is other evidence to support this impression. However, some of the other chants in our sample illustrate cases where portions sharing the same bet have a great deal more in common with each other than the two portions in Table 8.

Princeton University

I NGRID MONSON

EVIDENGE FROM THE MODERN ORAL T R A D I T I O N

Ethiopian Christian chant is an example of a musical system whose notation was never intended to replace oral transmission. The alphabetic abbreviations known as $m \partial l \partial k k \partial t$ are used to index a corpus of conventionalised melodic phrases, which are themselves drawn from whole source chants. Unless the Ethiopian musician is performing the source portion itself, he must accommodate new text to the phrases while singing. Competence in Ethiopian chant performance, accordingly, is acquired by memorising a repertory of phrases, learning the alphabetical abbreviations for these melodies, and developing the ability to recall and sing these phrases on

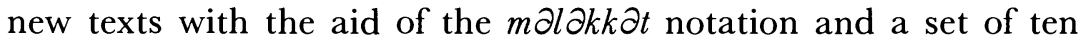
additional signs, $y \varepsilon f i d \varepsilon l$ $q \partial r s$ ', here termed 'conventional signs'. 
Oral and written transmission in Ethiopian Christian chant

Study of the notational system is carried out only after the Ethiopian church musician has learned many portions as whole chants. The notation, once learned, appears to facilitate the acquisition of additional repertory.

Transcriptions of eighteen liturgical portions, a pedagogical list of $558 \mathrm{~m} \partial l \partial k k \partial t$ from the Bethlehem school (hereafter called the dictionary), and a comparative list of fifty-seven $m \partial l \partial k k \partial t$, including performances by practitioners in the Qoma and Achaber schools, will be used here to illustrate various features of the musical system as perpetuated in the Ethiopian Christian oral tradition.

The first part of this discussion attempts to define 'mode' as it applies to Ethiopian chant. The second part discusses a single liturgical portion and its notation in detail. In the final section, a comparative sample is used to identify both the range of variation between renditions by one musician at different times, and between three different musicians performing the same material.

A definition of mode. The Amharic word salt, which can be rendered as 'mode', applies to the indigenous classification of the $m \partial l \partial k k \partial t$ and portions into three musical categories. The word zema, which in its general sense means sacred chant, can also be used to mean mode. A metaphor associating the three modes with the Holy Trinity is operative in Ethiopian chant: the $g \partial^{e} \partial z$ mode represents God the Father; ${ }^{c} \partial z l$ God the Son; and Eraray the Holy Spirit. ${ }^{61}$

Musically, $g \partial^{e} \partial z$ distinguishes itself from eraray and ${ }^{e} \partial z l$ by possessing a different background pitch set. Eraray and ${ }^{~} \partial z l$ are, in turn, differentiated from each other by liturgical function and register: they both use the same background pitch set, but ' $\partial z l$ is employed primarily during Lent and Holy Week.

For the Ethiopian church musician the identity of the modes is

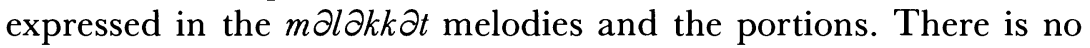
indigenous classification of the pitch material within these melodies, although a pitch set differentiation between $g \partial^{c} \partial z$ and the other modes is tacitly and rigorously observed in practice. My description of pitch usage in the Ethiopian modes is therefore an

${ }^{61}$ Lepisa, 'The Three Modes', pp. 163-6. 
analytical convenience and is not to be confused with indigenous notions of scale or melody type.

$G \partial^{e} \partial z$ is the most frequently occurring mode, accounting for approximately half (287) of the 558 signs in the dictionary. Example 7 sets out the pitch set used in $g \partial^{\circ} \partial z$. It consists of a series of thirds ${ }^{62}$ represented here as $a^{\prime}-c^{\prime \prime}-e^{\prime \prime}$ (in semibreves) which serve as the most common points of resolution for $g \partial^{c} \partial z$ melodies ( $g \#$ occasionally appears as a point of resolution as well). The chromatic auxiliary notes around the outer fifth $\left(g \#^{\prime}\right.$ and $b b^{\prime}$ around $a^{\prime}$, and $d \#^{\prime \prime}$ and $f^{\prime \prime}$ around $e^{\prime \prime}$ ) embellish this mode, as can be seen in the example $m \partial l \partial k k \partial t$ shown in Example 7. There is often indifference over whether embellishment of the note is above or below the principal note, suggesting that for the Ethiopian musician variations of this type do not compromise the melodic identity of the sign (cf. example $m \partial l \partial k k \partial t \mathrm{G} 13$, final three notes, and G25 on syllable $s \varepsilon)$. The middle member of the series of thirds $\left(c^{\prime \prime}\right)$ is not decorated by half-steps. This note is the returning tone, or final in the $g \partial^{\circ} \partial z$ mode. ${ }^{63}$ In the notation, cadential patterns and the returning tone are indicated with $\varepsilon n b \partial r$, one of the ten conventional signs. The true distance of this pitch from the first in the series of thirds tends to be slightly larger than a minor third. On occasion it is as large as a major third.

62 The expression 'series of thirds' is a modification of Curt Sachs's notion of 'chain of thirds' (Sachs, 'Primitive and Medieval Music: a Parallel', JAMS, 13 (1960), pp. 42-9; The Wellsprings of Music, ed. J. Kunst, repr. of 1962 edn (New York, 1977)). It is intended to describe the pitches which serve as points of melodic resolution in the $g \partial^{e} \partial z$ mode, in the absence of an indigenous term. Sachs defines 'chain' as follows: 'the melody has a formative kernel, usually a third or fourth; when the singer expands the range of his melody beyond this kernel, he often feels compelled to add a similar interval above or below, thus creating a double third or a double fourth and, onward, ... [includes possibility of chain of 3-6 like intervals]' ('Primitive and Medieval Music', p. 45). Sachs's exposition requires revision for two reasons: (1) it does not include a notion of octave duplication (which occurs frequently in Ethiopian chant), and (2) it is used to articulate a theory for the historical development of melody cross-culturally on the speculative and evolutionary assumption that melodies expanded outward from small intervals and are filled in from larger ones (The Wellsprings of Music, pp. 143-58, 72, 512). H. van der Werf, The Emergence of Gregorian Chant (Rochester, NY, 1983), pp. 10920, has apparently borrowed this term from Sachs along with aspects of Sachs's ideas concerning historical priority as applied to Gregorian chant. Sachs, however, includes the notion of points of melodic repose connected by 'passage' notes ('Primitive and Medieval Music', p. 45), which is useful in the Ethiopian case and is not included in the idea of 'octave species'. I thank Peter Jeffery for citations and for assistance in clarifying this point.

63 In Ethiopian secular music, the term melash means 'returning tone' (A. Kebede, 'The Bowl-Lyre of Northeast Africa - Krar: the Devil's Instrument', Ethnomusicology, 21 (1977), pp. 389-91. 
Oral and written transmission in Ethiopian Christian chant

Example 7. 'Mode' in Ethiopian chant (source: dictionary of $m \partial l \partial k k \partial t$ performed by Berhanu Makonnen between June and October 1975)
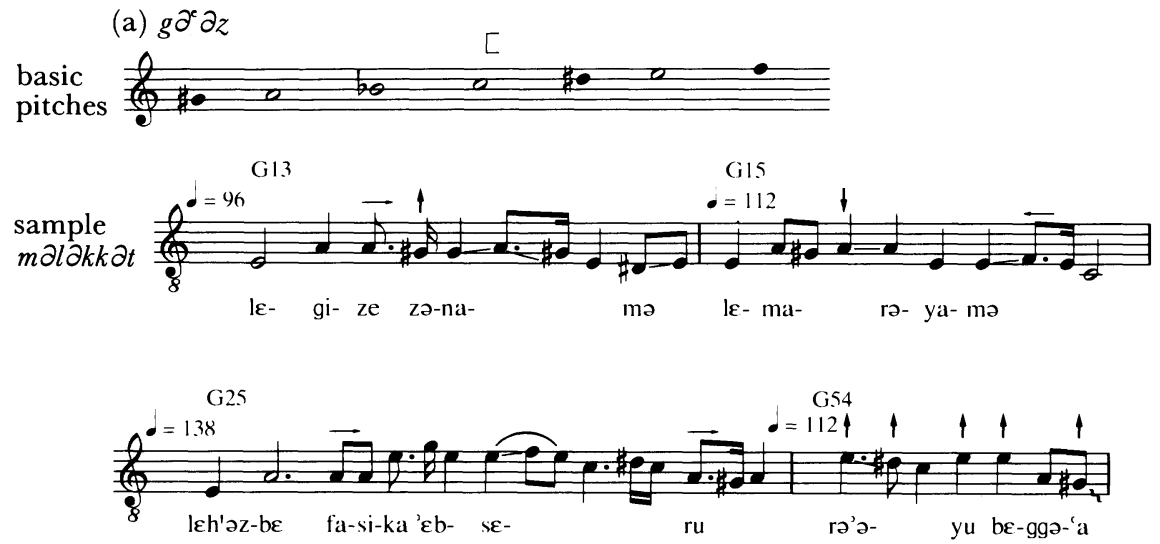

(b) Eraray; ' $\partial z l$

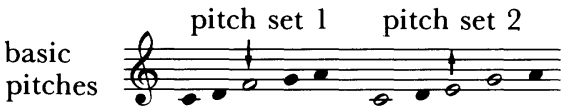

A58 (dictionary)

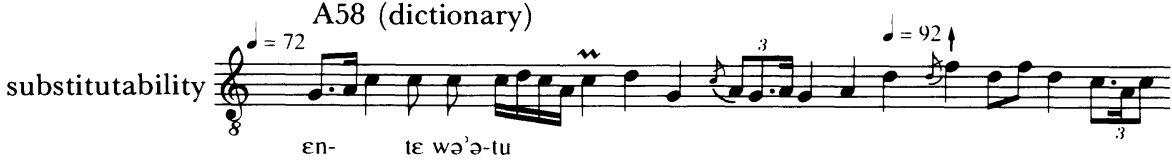

A58 (excerpt from portion 3)

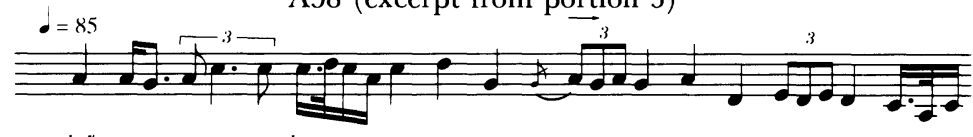

dah-nə- nu zəs-ku
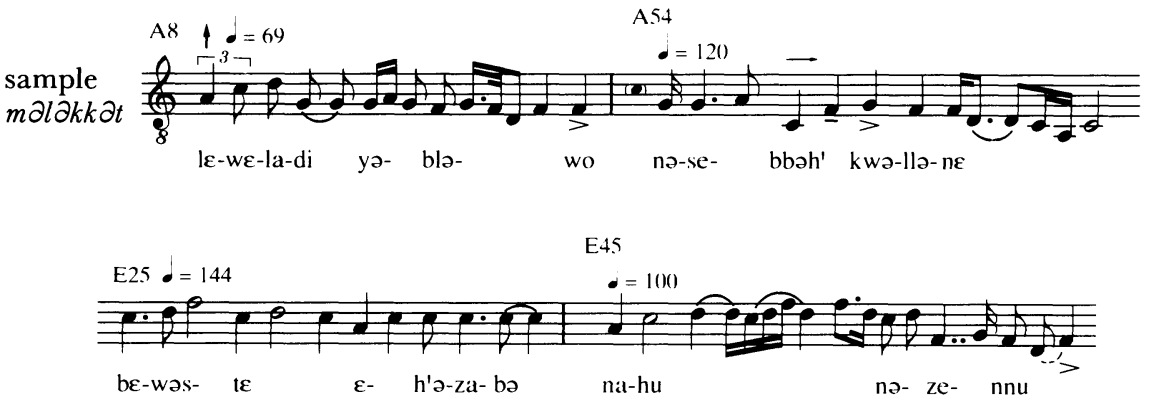
Defining eraray and ' $\partial z l$ is more problematic, largely owing to difficulties in translating Ethiopian intonation into Western notation. Eraray and ' $\partial z l$ both use the same pitch set, $c^{\prime}-d^{\prime}-f^{\prime}-g^{\prime}-a^{\prime}$ or $c^{\prime}-d^{\prime}-e^{\prime}-g^{\prime}-a^{\prime}$, as rendered in staff notation (see Example 7). Ambiguity in these modes, from the analyst's perspective, is the product of two factors. First, the actual intonation of the intervals $d^{\prime}-f^{\prime}$ and $d^{\prime}-e^{\prime}$ is often in between these two Western pitches, so much so that whether the Western ear should resolve the ambiguity towards the second or the minor third in the transcriptions has often been a point of disagreement in the research team. We had the interval measured on a Fairlight Voicetracker. It is indeed often exactly halfway between a major second and a minor third. ${ }^{64}$ These two pitch sets, rendered in staff notation, are often observed as substitutes for one another. See, for example, Example 7, where the melody of sign A58 is shown in the dictionary using pitch set 1 and in one of the portions with pitch set 2. The signs proceed identically until the fifth pitch of the set is introduced. Secondly, the typical cadential gesture of a descent and return of a minor third can occur at two places within any given form of the pitch set: $c^{\prime}$ and $f^{\prime}$ within set 1 , or $c^{\prime}$ and $g^{\prime}$ in pitch set 2, making it difficult to establish a returning tone for any $m \partial l \partial k k \partial t$ in isolation. ${ }^{65}$ Selecting a comparative transposition level for the $m \partial l \partial k k \partial t$ was difficult, particularly in light of the fact that eraray is additionally said to be the mode with the highest register ${ }^{66}$ Only in the portions, which indicate returning tone with the symbol $\varepsilon n b \partial r$, has it been possible to observe the apparent predominance of pitch set 2 in characterising the mode. It may, in fact, be better to think of these modes as a pentatonic collection with a variable third degree.

The performance of a liturgical portion. To illustrate the many musical issues involved in performing Ethiopian chant, liturgical portion 7 from our sample will be examined in some detail. Portion 7 is an Engergari for Christmas in the $g \partial^{c} \partial z$ mode. The word Engergari is evidently derived from an Amharic word which connotes agitation or excitement, ${ }^{67}$ and is often used for chants that are linked to major feast days.

64 We thank Dr Kathryn Vaughn, who carried out this work at the University of California, Los Angeles.

65 This cadential gesture is observable at the end of each $m \partial l \partial k k \partial t$ in Example 7.

66 Lepisa, 'The Three Modes', p. 166.

67 Leslau, Concise Amharic Dictionary, p. 209. 
Oral and written transmission in Ethiopian Christian chant

Figure 6 Notation of portion 7, engergari for Christmas (Yeziq Mes' $h^{\prime} a f$, Addis Ababa, 1962 E.c.)

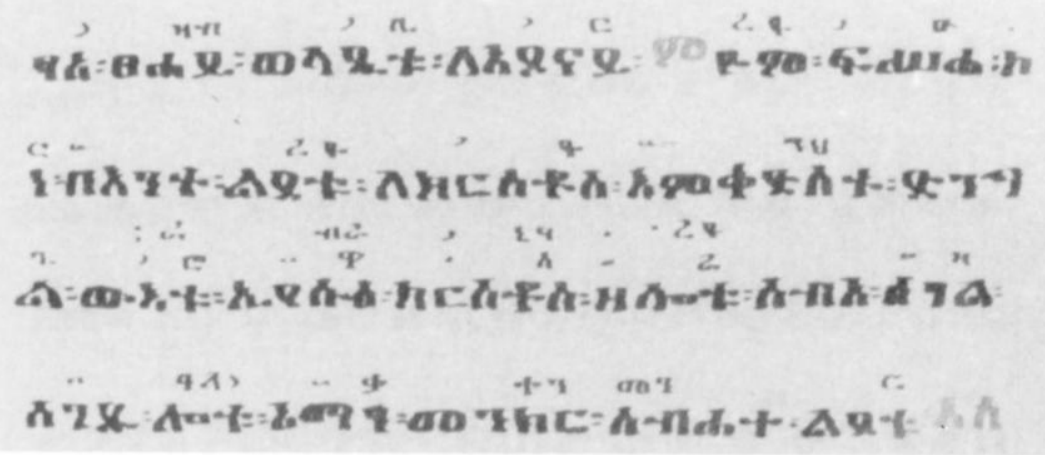

Translation: There is joy today because of the birth of Christ from the Holy Virgin. He is Jesus the Christ before whom the Magi prostrated themselves. Truly the glory of his birth is wonderful. (translation by Getatchew Haile)

An internal textual-musical repeat called a molt'an is a formal feature that portion 7 shares with many others in our sample. The musical repeat is usually notated in one of two ways - either with a double line of notation over the part of the text to be repeated, or by placing the abbreviation for malt'an $(m \partial l)$ at the end of the portion. When the latter convention is used, the second part is written out again. In our example, Eleqa Berhanu sang from a source called Yeziq Mes' $h$ 'af, a collection of important parts of the $D$ gggwa for holidays. ${ }^{68}$ This particular source has an incomplete double line of notation beginning at the molt'an; consequently, Eleqa Berhanu did not sing the repeat. The molt'an, however, is notated in all but five of the manuscripts examined by Peter Jeffery. The notation that Eleqa Berhanu sang from is shown in Figure 6. Throughout the portions analysed for this project, the music for the malt an repeat is generally very similar to the first presentation, despite some notational contrast.

Portion 7 is one of the shorter chants in our sample, partly because Berhanu Makonnen chose not to sing the repeat. The top line of each system of Example 8 presents a transcription of Eleqa Berhanu's singing of portion 7 . The bottom lines show the diction-

68 Addis Ababa, 1962 E.c., 20F in our MS sample. 
Kay Kaufman Shelemay, Peter Jeffery, Ingrid Monson

Example 8. Portion 7, engergari for Christmas (source: performed by Berhanu Makonnen, 23 September 1975)
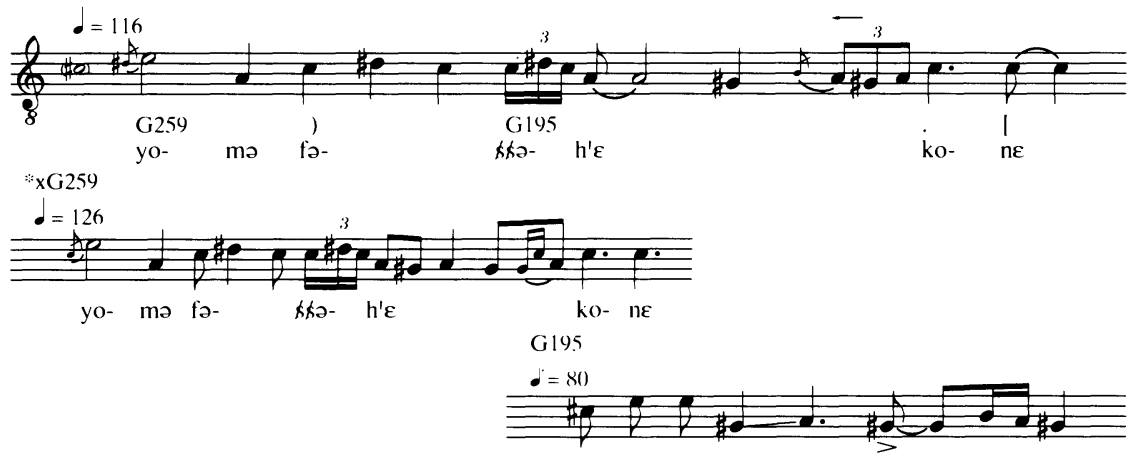

wย- yว- wa-wwว 'u
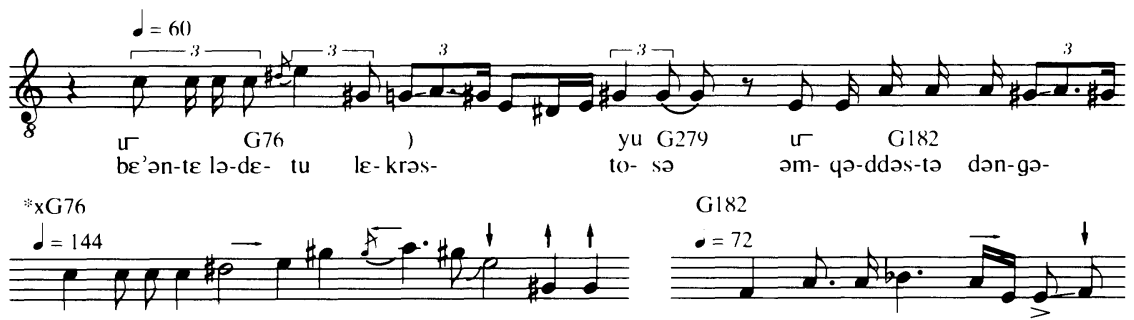

b $\varepsilon^{\prime}$ an-t $\varepsilon$ lo-d $\varepsilon-\mathrm{tu}$

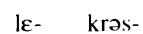

G279

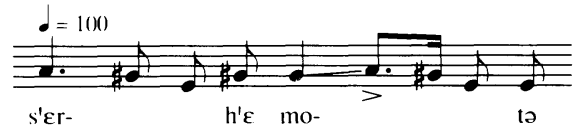

(M)

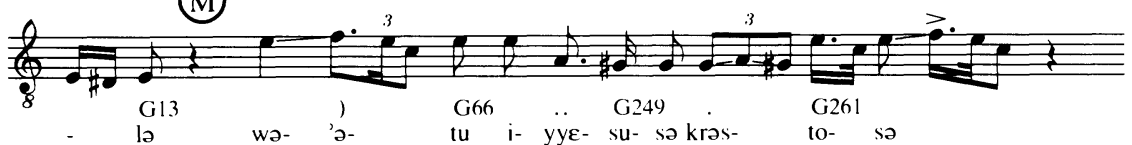

G66

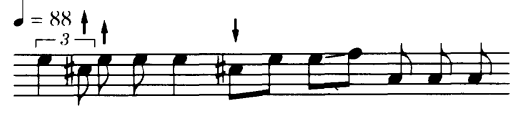

be- $\quad \mathrm{d} \varepsilon$ - ro $l \varepsilon-\quad \mathrm{p}^{\prime} \mathrm{e}-\quad$ t'ro-sa

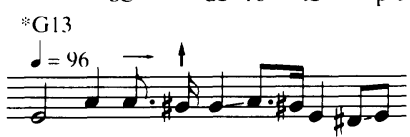

le- gi-ze zə-na-

mə
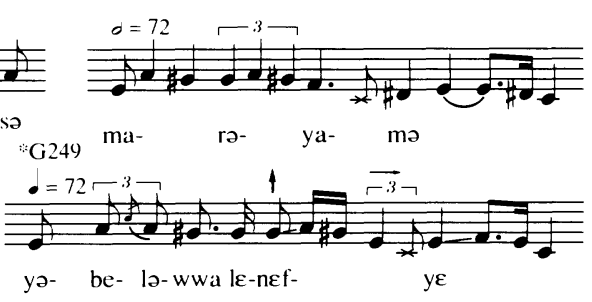

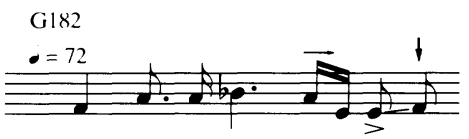

$k \varepsilon-m \varepsilon$ nว- hə-

เว 
Oral and written transmission in Ethiopian Christian chant

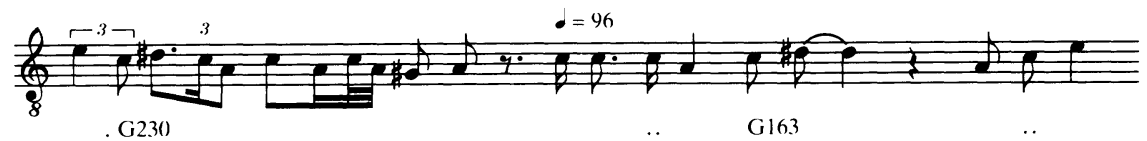
ze- lo-

$\mathrm{ttu}$

$\mathrm{s} \varepsilon-\mathrm{b}^{\prime} \varepsilon \quad \stackrel{\mathrm{s}}{ } \boldsymbol{-}-$

ge- la

$s \varepsilon-g \varepsilon-$

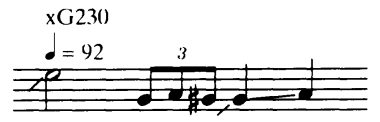

ze- lo- ttu

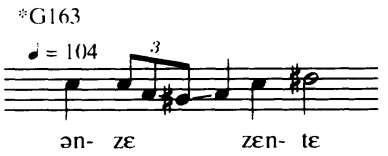

วn- $z \varepsilon$
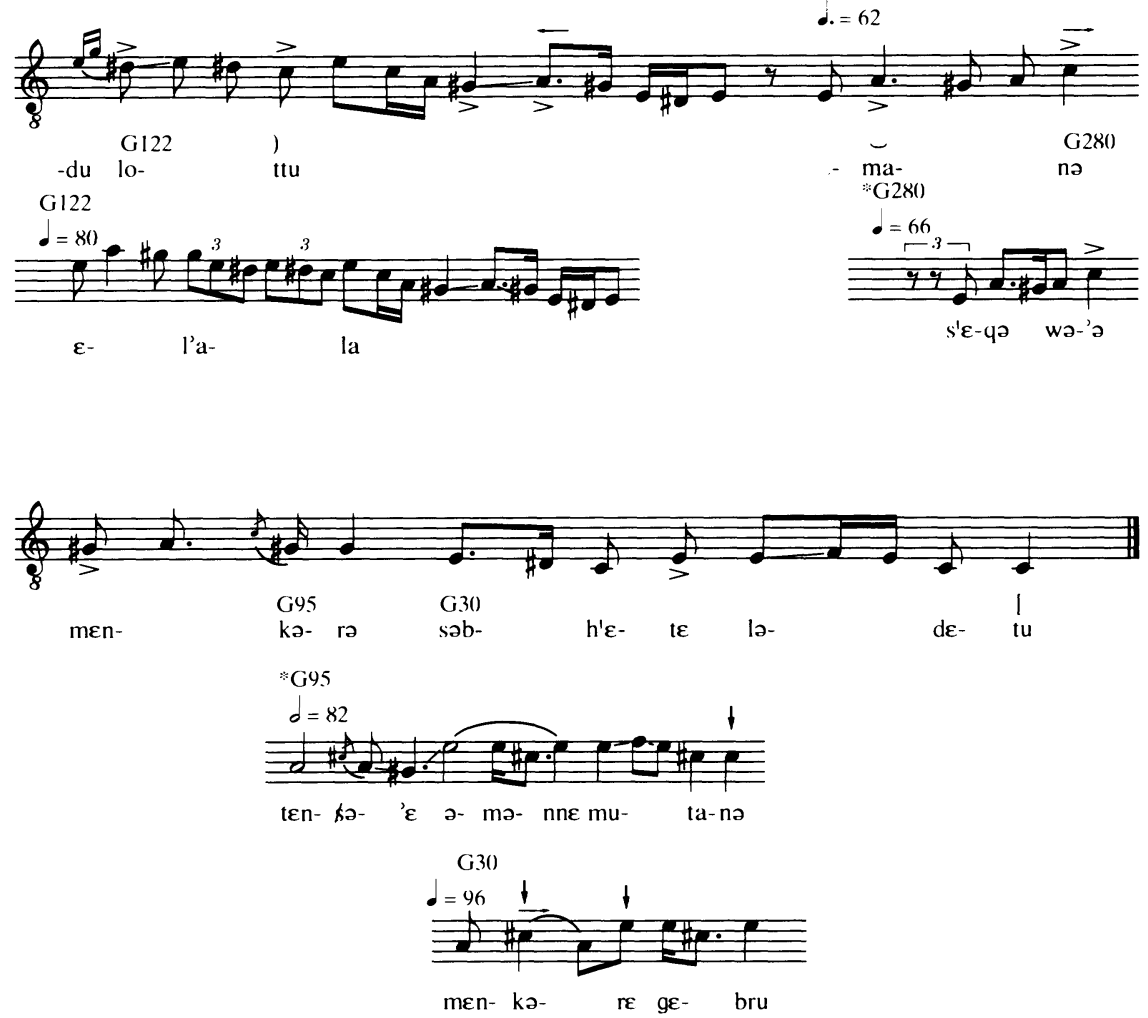
ary entry for each $m \partial l \partial k k \partial t$. The $m \partial l t$ 'an would begin on system 3 (marked with an $\mathbf{M}$ ). In each section, portion and malt'an, the $m \partial l \partial k k \partial t$ move to gradually lower points of resolution. In the

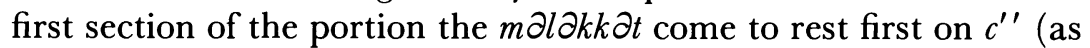
notated here), then $g \sharp^{\prime}$, and finally on $e^{\prime}$ just before the malt'an. At this point Berhanu returns to the opening $e^{\prime \prime}$, emphasising the high register until coming to rest on $c^{\prime \prime}$ (beginning of third system). From this moment onwards, Berhanu sings a gradually lower set of melodic resolutions that are more extended than those of section 1 . The melisma on lo of zelottu (beginning of system 4) comes to rest on $a^{\prime}$; the melisma on $t u$ of lottu (beginning of system 5) comes to a halt on $e^{\prime}$. The last phrase continues the descent to come to rest on $c^{\prime}$, the lowest note of the portion. This sequence of progressively lower melodic resolutions with lengthier melismas in the second half of portions or subsections of portions is a common feature of $g \partial^{e} \partial z$ mode portions, and appears to be a conventionalised practice.

Portion 7 exhibits a very high degree of correspondence between the dictionary $m \partial l \partial k k \partial t$ and the signs as performed in the portion. Allowing for octave displacement, eight signs match the dictionary entries with great exactness. These signs are marked with an asterisk on the dictionary lines of Example 8. Three signs are examples of $s \partial r \varepsilon y u$, a designation indicating that this occurrence is the source

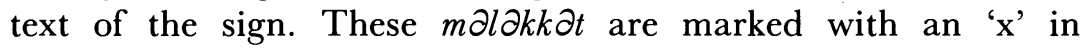
Example 8.

In system 2 and the beginning of system 3 , it will be noted that signs G279, G182 and G13 apply to the same musical phrase. The

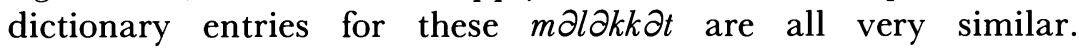
Since G13 is the only sign that begins on the same pitch as the portion melody, it appears that Eleqa Berhanu has chosen to sing G13 and to bypass G279 and G182. Likewise, in system 3, G249 and G261 resemble each other very closely. Berhanu has apparently chosen G261, although in this case the signs are nearly identical. Such situations, including examples where the skipped $m \partial l \partial k k \partial t$ does not resemble the chosen sign, are quite common throughout the eighteen portions in our sample. A knowledge of which $m \partial l \partial k k \partial t$ are substitutable or equivalent to one another appears to be essential to the performance practice of Ethiopian chant.

In performance, one also finds contraction and expansion of the 
melodies associated with the signs. The portion melody for G66 (system 3) makes use of only the first word of the dictionary entry for the sign (cf. w $\partial^{\prime} \partial t u$ in the portion with $b \varepsilon d \varepsilon r o$ in the $m \partial l \partial k k \partial t$ ). In contrast, the portion melody for G230 (see system 4, zelottu) represents an expansion of the dictionary version of the $m \partial l \partial k k \partial t$. Finally, G122 (system 5, beginning) corresponds to the last part of the dictionary entry only: the melisma on the last syllable of the sign.

The sign in the margin of the notation (ri) is a bet or 'house' sign. It indicates a melodic incipit, which in this case exactly matches the $m \partial l \partial k k \partial t$ G259. ${ }^{69}$ In portions with halleluyas, the bet indicates the melody to which a halleluya is sung. In some portions in our sample these incipits recur at phrase beginnings, even if the beginnings of the $m \partial l \partial k k \partial t$ are somewhat modified in the process. In this way the bet seem to provide a source of melodic continuity and may aid the singer in synthesising the portion.

For most signs, the $m \partial l \partial k k \partial t$ melody is applied to a different text and consequently the singer must adjust the text of the portion to the melody of the sign. The textual placement in the sign seems to guide that of the portion, but often discrepancies exist between the length of the portion text and that of the sign. Syllabic quantification does not appear to play a critical role in such accommodation. The conventional signs of $y \varepsilon f i d \varepsilon l q \partial r s^{\prime}$, however, appear to play an important role in textual placement.

Example 9 presents examples of five of the ten conventional signs drawn from the portion sample. The musical contexts in which these signs appear in the portions have helped us to draw some tentative conclusions about their functions. I will start with the most consistent sign, ch' $\partial r \varepsilon t$ (see Example 9a). In every case,

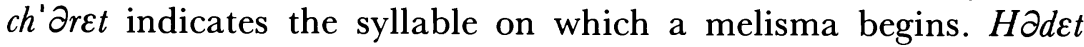
(Example 9b) apparently indicates that many syllables must be

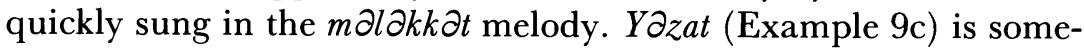
what puzzling. It occurs frequently in the portion sample, yet not in a uniform musical context. Berhanu's definitions - 'you must stop' or 'you must hold your voice on one letter"

69 This bet corresponds to one that Berhanu Makonnen did not sing (B97.3, ri), possibly because he regarded it as duplicating B9l (quri) to which the portion's opening melody corresponds exactly.

${ }^{70}$ K. K. Shelemay, unpublished fieldnotes and recordings: interviews with Berhanu Makonnen, 2 June-10 October 1975 (Addis Ababa), 7 June 1979 and n.d., p. 7. 
Kay Kaufman Shelemay, Peter Jeffery, Ingrid Monson

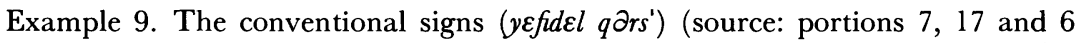
as performed by Berhanu Makonnen, 3 September, 27 June and 12 July 1975)

(a) $\left.c h^{\prime} \partial r \varepsilon t\right)$
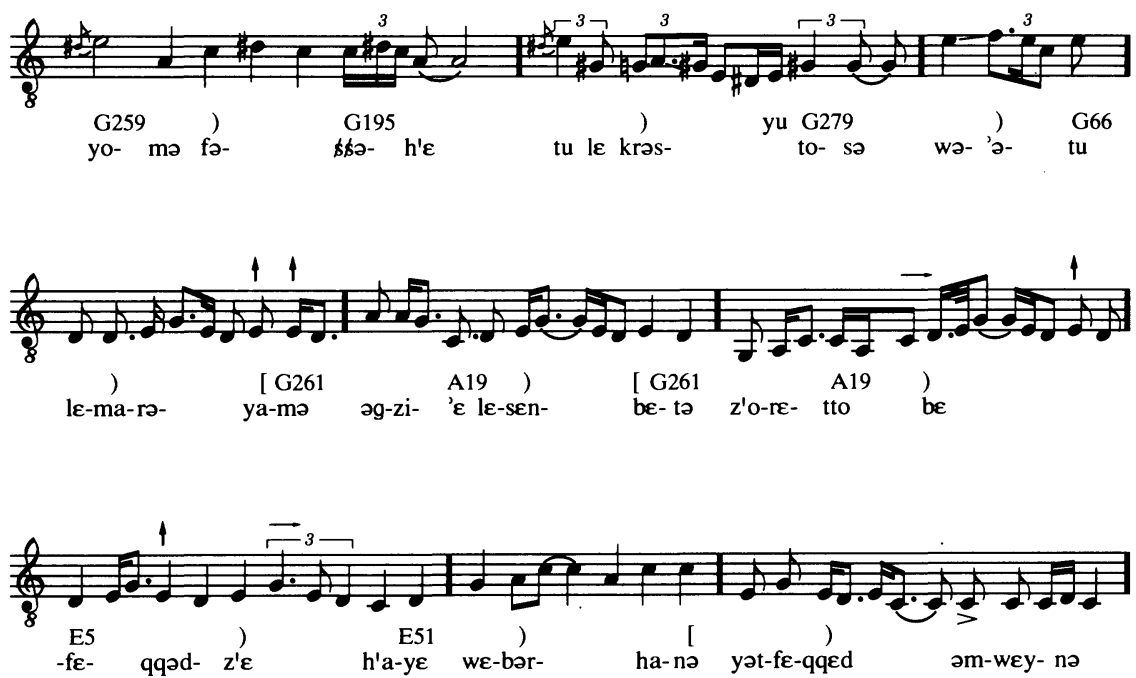

(b) $h \partial d \varepsilon t \sim$
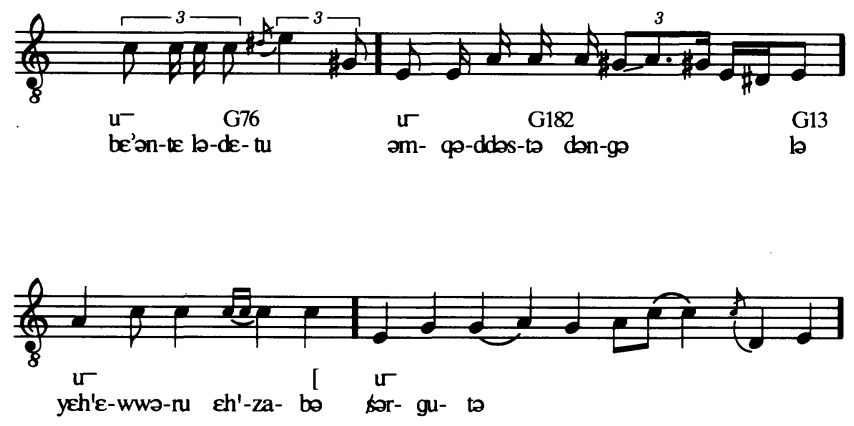

(c) $y \partial z a t$.

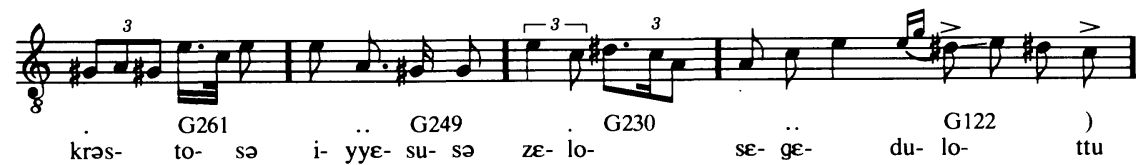


Oral and written transmission in Ethiopian Christian chant

(c) continued
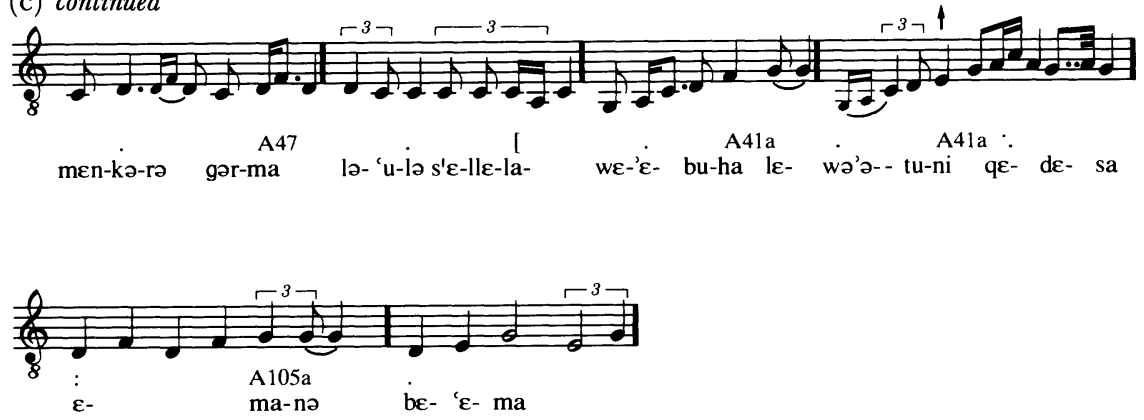

(d) $d \partial r s \cap$
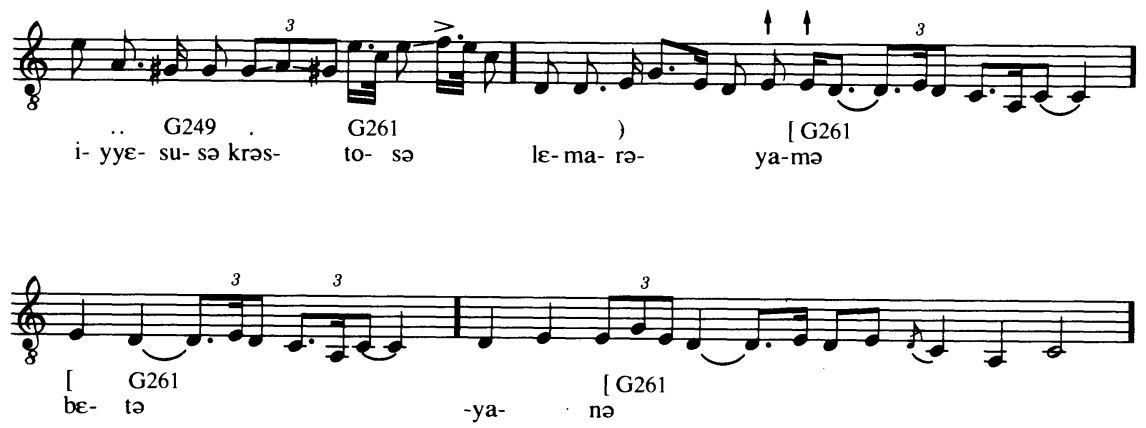

(e) $\varepsilon n b \partial r[$
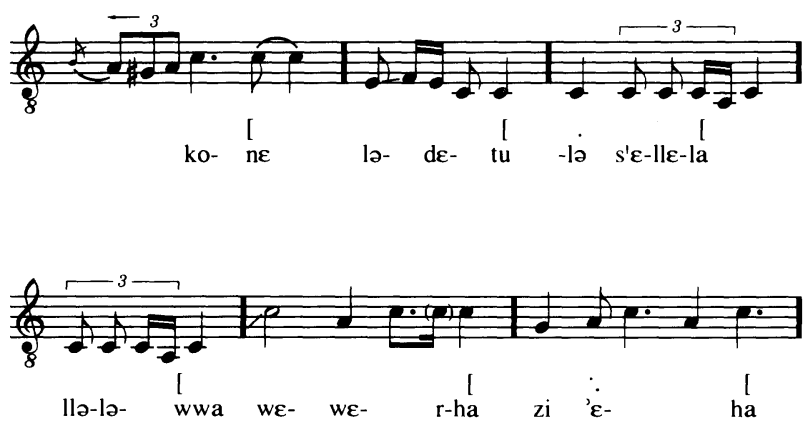

Note: these examples are drawn from portions in each mode; portion 7 is in

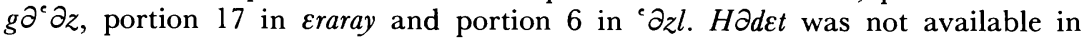
all three portions. 
Kay Kaufman Shelemay, Peter Jeffery, Ingrid Monson

it may indicate a stressed or prolonged syllable, although in many portions this is not very audible. Two conventional signs, $d \partial r s$ and $\varepsilon n b \partial r$, have specific melodies associated with them (Example 9d and e). These signs, which indicate that a melodic cadence should be sung, have versions appropriate to each mode: one version serves for eraray and ' $\partial z l$; another serves for $g \partial^{e} \partial z$. D $\partial r$ s actually has an equivalent in the $m \partial l \partial k k \partial t$ : G261; several other $m \partial l \partial k k \partial t$ appear to have functions that relate to the conventional signs as well. This suggests that there has been a tendency for the $m \partial l \partial k k \partial t$ to incorporate some of the musical features originally indicated by conventional signs.

The most important observations emerging from this discussion are (1) that the Ethiopian musician makes many of his own decisions in the course of realising the $m \partial l \partial k k \partial t$, (2) that the conventional signs are most important in textual placement and indication of important melodic cadences, (3) that musical structure follows textual structure very closely and (4) that the bet may play an important role in the musical continuity of portions which use them.

A comparative sample. Fifty-seven $m \partial l \partial k k \partial t$ sung by representatives of the three extant regional styles - Bethlehem, Qoma and Achaber - provide comparative data for this study. The Bethlehem singer, Berhanu Makonnen, is the same musician who sang the dictionary. Comparing Eleqa Berhanu's renditions of the signs on two occasions several months apart allows us to see what type of variation occurs in his singing of the signs themselves. Of twentynine $m \partial l \partial k k \partial t$ in the $g \partial^{c} \partial z$ mode, for which we have comparative information, only two exhibit variations that threaten the identity of the sign. Two are more extended in one rendition than the other.

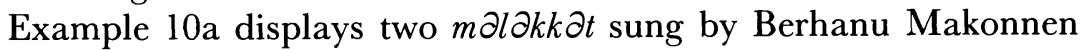
three months apart. G198 shows variation that affects the identity of the melody, while G219 is an example of melodic extension in one version. Allowing for equivalences in mode, general rhythmic character and octave displacement, the remaining $m \partial l \partial k k \partial t$ are nearly identical. In the eraray and ' $\partial z l$ m $\partial l \partial k k \partial t$ in the sample, extension of the sign is the only significant type of variation. Eleqa Berhanu is remarkably consistent in his rendition of the signs.

The melodies of the $m \partial l \partial k k \partial t$ as compared among the three 
Oral and written transmission in Ethiopian Christian chant

Example 10. Comparative renditions of $m \partial l \partial k k \partial t$

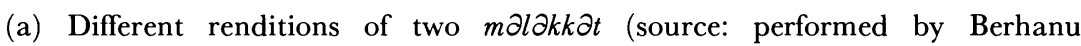
Makonnen, 2-7 June and 8 September 1975)

G198

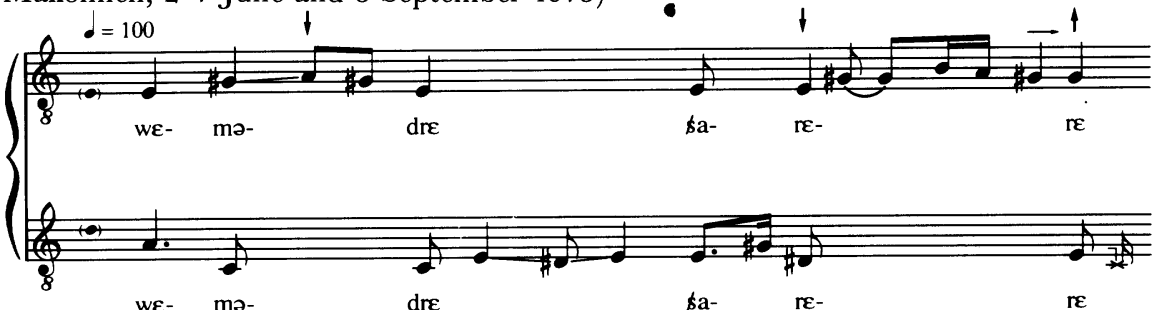

G219

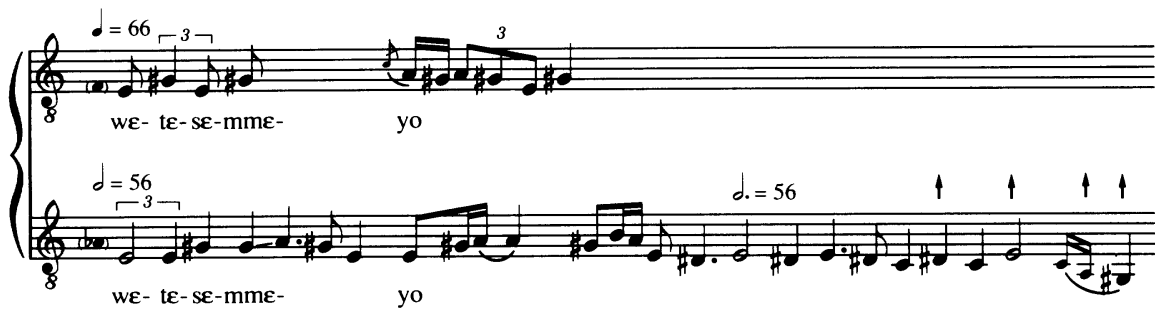

(b) Comparative renditions of four malakkat in Bethlehem (B), Qoma (Q) and Achaber (A) styles (source: performed by Berhanu Makonnen, Berhanu Abiye and Tekle Mesheshe, 8 September 1975)

G170
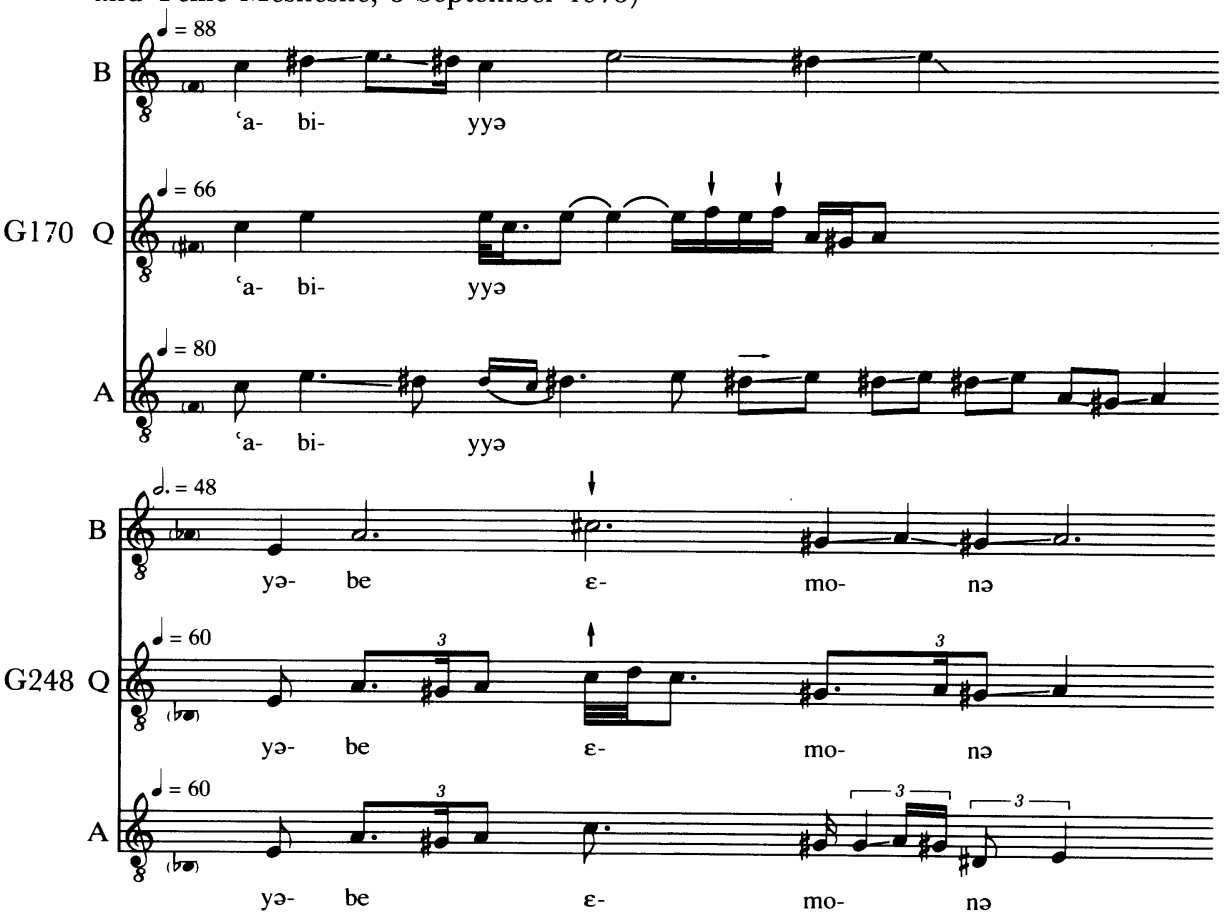
Kay Kaufman Shelemay, Peter Jeffery, Ingrid Monson

Example 10 continued

A97

B

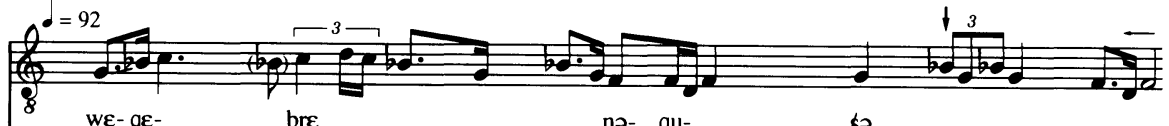

we-ge- bre nə- gu-

\$2

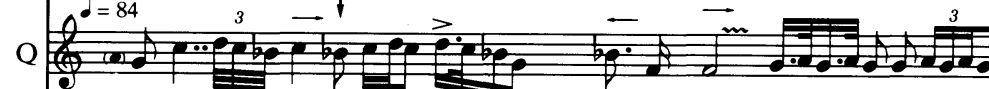
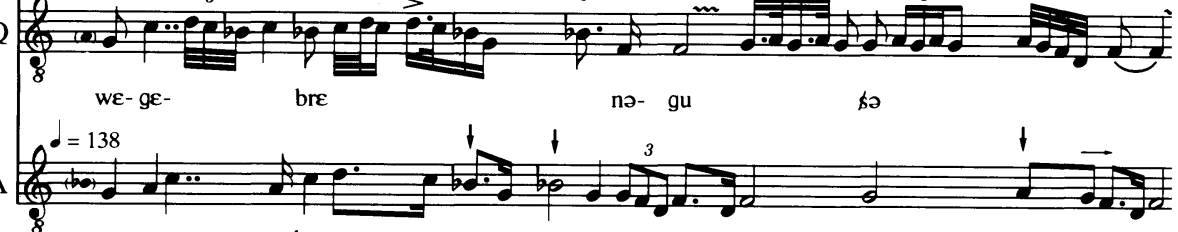

we-ge- bre

nว- gu-

\$ว

A140

B

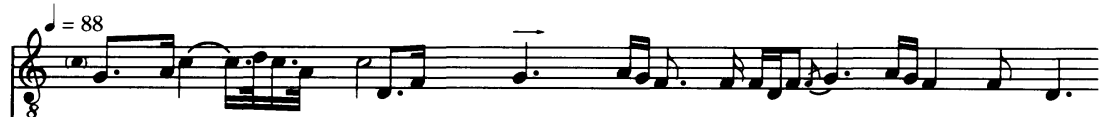

fe-

nnu

2- de-

$\mathrm{k} \varepsilon$

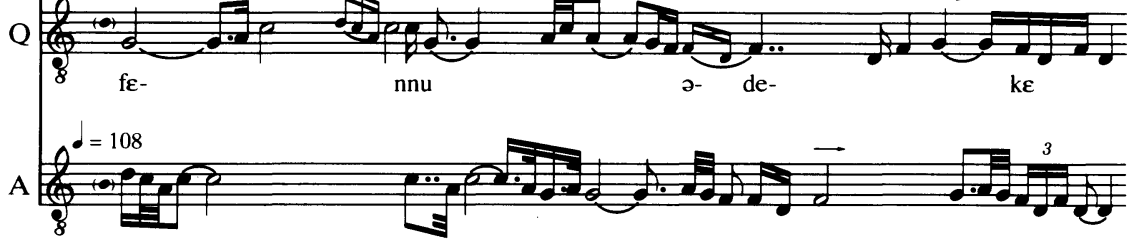

fe-

nnu

ว- de-

$k \varepsilon$

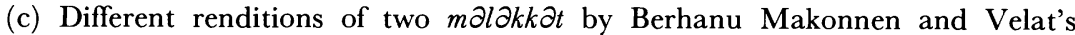
informant (sources: performed by Berhanu Makonnen, 2-7 June 1975; transcribed in Velat, Études sur le Me eräf, p. 629; note: the two items from Velat have been transposed for purposes of comparison)

G146

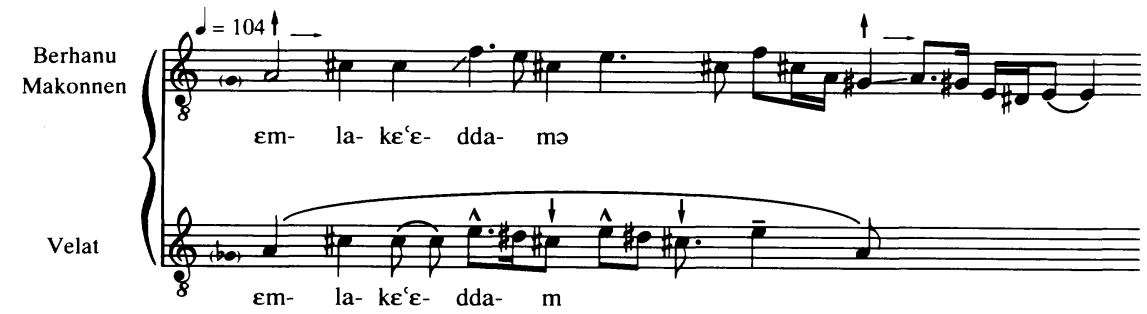

G213

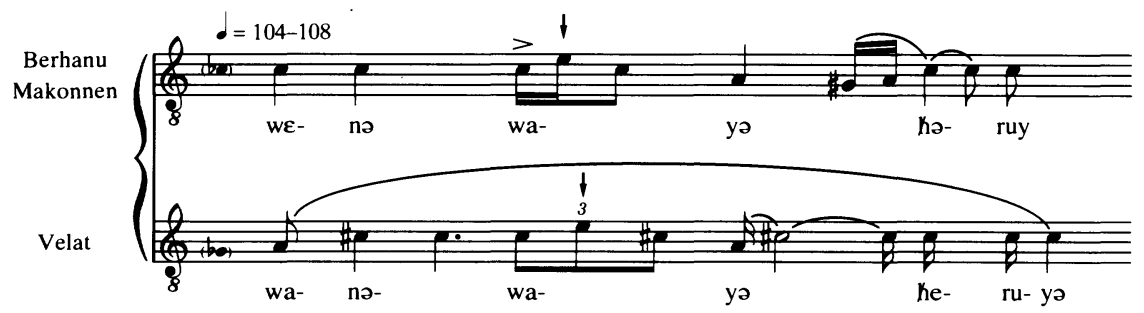


Oral and written transmission in Ethiopian Christian chant

regional styles - Bethlehem, Qoma and Achaber - exhibit greater

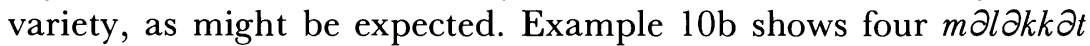
from the comparative sample. The Qoma and Achaber styles tend to be more melismatic and extended than the predominant Bethlehem style, confirming singers' testimony that these two minority styles are 'longer' than Bethlehem. There is both sufficient general and specific correspondence between the signs, however, to suggest that the three schools are closely related (cf. G170 and G248; A97 and A140). While both oral tradition and documentary sources suggest that Bethlehem is the oldest style, it is important to note that similarities are probably the product of both common ancestry and contact in the modern performance tradition. It is not uncommon for church musicians from different regional styles to sing in the same church in the Ethiopian capital. ${ }^{71}$

There is one more comparative sample that should be mentioned. In 1951, Bernard Velat recorded an accomplished Bethlehem debtera singing more than 500 of the $m \partial l \partial k k \partial t$. He published transcriptions of about half of them..$^{72}$ I have compared many of these transcriptions with my own and have found a great deal of consistency in the $m \partial l \partial k k \partial t$. Example 10c includes two $m \partial l \partial k k \partial t$ as rendered by Berhanu Makonnen and Velat's informant. While there is more variation than between Berhanu's two samples, given three months apart, the melodies are readily recognisable within the parameters previously mentioned. These transcriptions, made

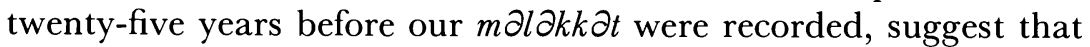
the Ethiopian notational system succeeds in transmitting a relatively stable musical corpus. The $m \partial l \partial k k \partial t$ seem to confine melodic variation to relatively small units.

University of Chicago

\section{GONGLUSIONS}

These observations, and indeed our entire project, have only scraped the surface of Ethiopic chant, which is in almost every way a subject as vast as Gregorian chant. We felt like archaeologists

71 Shelemay, unpublished fieldnotes and recordings: interviews with Berhanu Makonnen, Berhan Abiye and Tekle Mesheshe, 8 September 1975 (Addis Ababa).

72 Velat, Études sur le Méeräf, and Șoma Deggua (1969). 
digging test pits in order to plan an excavation; the excavation itself has barely even begun.

Concerning the nature of Ethiopian chant as a musical and notational system, it appears that it intends to transmit a relatively fixed corpus of chants with identifiable and reproducible melodic

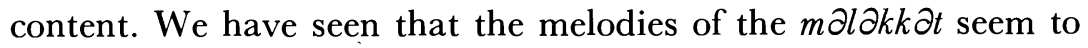
be quite stable within and between schools. The variations observed do not compromise the audible identity of the melody in most cases, and as such illustrate a distinction developed by Bruno Nettl and discussed by Harold Powers, between 'performing a version' of something and 'improvising upon something' ${ }^{73}$ Both are species of improvisation, in the sense that new melodic material may be constructed, but the intention of the former is to realise something relatively fixed and stable, while the latter actively values new invention. If, in order to describe degrees of improvisation, a continuum from nearly fixed to nearly random is posited, Ethiopian chant would occupy a position not far from the fixed end of the spectrum.

It may be asked to what extent the Ethiopian musician carries the musical tradition in his memory as whole chants, or to what

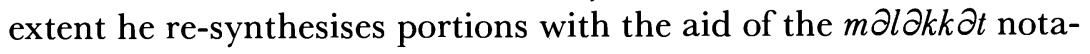
tion each time he performs. Whether the macro- or micro-context is viewed as the one that generates musical performance, the musical content of this tradition is carried completely in the memory of

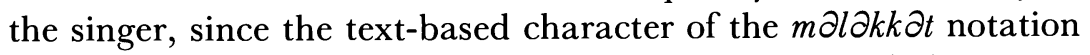
provides no visual indication of the contour of the melody.

If the $m \partial l \partial k k \partial t$ are seen as the building-blocks from which the singer creates a chant, there is ample evidence of oral compositional decisions. The Ethiopian musician must know which $m \partial l \partial k k \partial t$ resemble one another, which $m \partial l \partial k k \partial t$ are redundant, when to sing only the beginning or end of a sign, how to interpret the conventional signs, when and how to make use of the bet, how to place the text, and when melismatic extensions are appropriate all of this in addition to knowing and being able to recall the 500-plus $m \partial l \partial k k \partial t$ themselves.

If the macro-context is viewed as potentially more important, it might be argued that the Ethiopian musician does not synthesise

${ }^{73}$ H. Powers, 'Language Models and Musical Analysis', Ethnomusicology, 24 (1980), pp. $42-6$. 
a portion anew each time he sings, any more than a pianist is 'reading' a piece he or she has played innumerable times. The pedagogical tradition of the repertory also suggests this viewpoint: children learning the tradition begin by acquiring portions as a whole. Only after there has been some mastery at that level does the student begin a study of the notation. Apprehension of the notation, in turn, facilitates the learning of additional repertory.

If transmission in whole chants appears to be the most important process, however, the analyst must explain the persistence of the $m \partial l \partial k k \partial t$ system of notation over several centuries. Surely, a system that is not useful would not survive. It therefore seems only reasonable to suggest that the macro- and micro-musical memories of this tradition effectively reinforce one another; this, in fact, may be the central utility of the Ethiopian notational system. The Ethiopian church musician learns repertory in an order which integrates memories of whole chants with memories of chants in fragments - from two directions, as it were. If global memory fails, the $m \partial l \partial k k \partial t$ notation can serve as a means by which the musician re-synthesises vaguely remembered chants, and if local memory fails, recollection of the broader outline of the chant may help reconstruct the detail. There is probably much individual variation in which type of memory prevails.

The many contributions by individual musicians to the perpetuation and performance of the Ethiopian chant tradition took place within a broader historical framework. In the earliest recorded stage ('Stage I'), the different categories of portions were assembled into separate collections that could be organised either by melodic group or by liturgical year. The oldest such collection is from about the thirteenth century, and we do not know how much farther back such collections may once have existed, either orally or in writing.

By the fifteenth century, a representative portion had been identified for each melodic group ('Stage II'), becoming either a 'melodic model' in the case of Type I chants or the source of a bet or 'house' in the case of Type II. However, the 'models' system of Type I had achieved its standard form by the fifteenth century, whereas the house system of Type II - at least the written signs for it - did not stabilise until the sixteenth century. The first liturgical chant book incorporating all the categories is from the fifteenth century. 
The notation was apparently developed in the sixteenth century, and has been an integral part of chant manuscripts ever since. It was also in the seventeenth century that written lists of the melodic models and the houses began to be made ('Stage III') providing overall structures for both systems. Thus the Ethiopian chant repertory had achieved its classic written form by the seventeenth century, which is called the 'Gondar period' by Ethiopian historians after the name of the new Ethiopian capital established at Gondar by the Emperor Fasilidas in 1635.

There is no doubt that the Ethiopian chant tradition and changes in its transmission process have been directly shaped by events in Ethiopian cultural history. The emergence of notation in the sixteenth century, although perhaps anticipated by earlier developments, appears to represent a direct attempt to sustain the musical tradition in the tragic aftermath of the Muslim invasion.

Available documentary sources suggest that the first seventy-five years of the Gondar period, culminating in the reign of Emperor Iyasu I, saw the construction of churches and castles as Gondar both influenced and absorbed an array of regional styles. ${ }^{74}$ Royal support and demand for artistic and liturgical artefacts encouraged musicians to produce more notated manuscripts just as it encouraged the development of distinctive Gondarene styles of painting and iconography. ${ }^{75}$ The technological innovation represented by the $m \partial l \partial k k \partial t$ and their proliferation during the Gondar period can be seen as part of a broader cultural trend towards literacy, but one that at the same time continued to encode meaning simultaneously in oral transmission. Likewise, the increasing numbers of manuscripts containing musical notation dating from the eighteenth and nineteenth centuries are only part of the residue of a broader transition from oral transmission to increased use of writing. ${ }^{76}$

74 Merid Wolde Aregay, 'Southern Ethiopia and the Christian Kingdom 1508-1708, with Special Reference to the Galla Migrations and their Consequences' (Ph.D. dissertation, University of London, 1971), pp. 534-6, 542-8.

75 J. Leroy, Ethiopian Painting (London, 1967), pp. 28-30.

76 A recent analysis of the Amd $2 m$ ta Commentary corpus, a body of vernacular commentaries on $\mathrm{G} \partial^{e} \partial \mathrm{z}$ biblical and patristic texts, suggest that these commentaries were initially orally transmitted but reached their definitive written form during the Gondar era. R. Cowley, The Traditional Interpretation of the Apocalypse of St. John in the Ethiopian Church (Cambridge, 1983), pp. 23, 31. 
Oral and written transmission in Ethiopian Christian chant

Despite the decline of the Gondar monarchs' power in the late eighteenth century, their city continued to be a cultural centre and a site for musical innovation. But with the shift of the Ethiopian capital to Addis Ababa in 1887, the impact of governmental policies of centralisation ${ }^{77}$ also encouraged increasing consolidation of the chant tradition.

In the late twentieth century, few debteras perpetuate regional chant traditions as the Bethlehem style increasingly predominates. There is little doubt that the twentieth-century transmission of the chant tradition in Addis Ababa has served both to standardise and to normalise surviving oral tradition, while encouraging increasing notational detail. The 1974 revolution and the end of the monarchy that patronised the church introduced a dramatic new socioeconomic situation that has already altered transmission of the church musical system. ${ }^{78}$

Ethiopian chant is an example of a musical system whose notation was never intended to replace oral transmission. The $m \partial l \partial k k \partial t$ can be viewed as a conventionalised melodic repertory that assists and succeeds in the goal of transmitting a relatively fixed and stable liturgical corpus. The development of this notational system occurred in a specifically Ethiopian context and reflects particularly Ethiopian values concerning orality, flexibility and authority. The value of Ethiopian chant to comparative studies may lie in the portrait it provides of a highly constrained, notated, literate, yet orally transmitted repertory.

77 Levine, Wax and Gold, pp. 46-7.

${ }^{78}$ For a detailed discussion of the Ethiopian revolution, including its impact upon the church, see J. Harbeson, The Ethiopian Transformation: the Quest for the Post-Imperial State (Boulder, CO, and London, 1988). 